\title{
Can Short-sellers Predict Returns? Daily Evidence
}

\author{
Karl B. Diether, \\ Kuan-Hui Lee, \\ Ingrid M. Werner* \\ This Version: November 17, 2005 \\ First Version: June 17, 2005 \\ Comments are Welcome
}

\begin{abstract}
We test whether short-sellers in Nasdaq-listed stocks are able to predict future returns based on new SEC-mandated data for the first six months of 2005. There is a tremendous amount of short-term trading strategies involving short-sales during the sample: Short-sales represent 27 percent of Nasdaq share volume while monthly short-interest is about 3.1 percent of shares outstanding (5.5 days to cover). Short-sellers are on average contrarian - they sell short following positive returns. Increasing short-sales predict future negative returns, and the predictive power comes primarily from small trades. A trading strategy based on daily short-selling activity generates significant returns, but incurs costs large enough to wipe out any profits.
\end{abstract}

${ }^{*}$ All three authors are at the Fisher College of Business, The Ohio State University. We are grateful for comments from Leslie Boni, Rudi Fahlenbrach, Frank Hatheway, David Musto, René Stulz, and seminar participants at the Ohio State University, the NBER Market Microstructure Group, and the University of Georgia. We thank Nasdaq Economic Research for data. All errors are our own. 
Many market observers accuse short-sellers of destabilizing markets by selling stocks (they do not even own) when prices are already trending downward, exacerbating the negative momentum. Issuers and journalists often characterize short-sellers' activities as immoral, unethical and downright un-American. ${ }^{1}$ Academics and traders instead argue that short-sellers stabilize security prices by selling stocks when prices exceed fundamental values, thus helping correct market overreaction. Short-term over-reaction could be caused by impediments to short-selling, as high costs of executing short-sales may result in stock prices reflecting the opinions of optimistic investors only (Miller (1977)). ${ }^{2}$ Some researchers have even argued that costly short-selling was one of the culprits behind the stock market bubble of the late 1990s (e.g., Ofek and Richardson (2003)).

In this study, we use the SEC mandated tick-by-tick short-sale data for 2,815 Nasdaq-listed stocks for the period January 3, 2005 to June 30, 2005 to test whether short-sellers are contrarian or momentum traders and whether they are able to predict future returns. We test these hypotheses by studying the link between short-selling activity and future returns and how short-sellers react to past returns on a daily level.

The literature on short-selling is growing rapidly. Most previous studies have used monthly stock-specific short interest data (e.g., Figlewski and Webb (1993), Figlewski (1981), Dechow, Hutton, Meulbroek, and Sloan (2001), Desai et al (2002), Asquith, Pathak, and Ritter (2005), and Singal and $\mathrm{Xu}(2005))$. There are three important problems with using monthly short interest data. First, the monthly reporting frequency does not permit researchers to study short-term trading strategies. Second, monthly short interest data does not distinguish between the short interest of dealers (who are exempt from short-sale restrictions) from that of customers. Third, the monthly short interest data does not permit a researcher to discern whether a high level of short interest means that short-selling is more expensive.

More recently, several authors have relied on proxies for short-sale constraints or demand (Chen, Hong, and Stein (2002) - breadth of ownership, Diether, Malloy, and Scherbina (2002), Nagel (2004) - institutional ownership, Lamont (2004) - firm's actions to impede short-selling), and even the actual cost of borrowing stock (D’Avolio (2002), Cohen, Diether, and Malloy (2005),

\footnotetext{
${ }^{1}$ For example, John Rothchild in the Bear Book said, "Known short sellers suffer the same reputation as the detested bat. They are reviled as odious pests, smudges on Wall Street, pecuniary vampires."

${ }^{2}$ See also Harrison and Kreps (1978), Hong and Stein (2002), Duffie, Garleanu, and Pedersen (2002), and Scheinkman and Xiong (2003).
} 
Jones and Lamont (2002), Geczy, Musto, and Reed (2002), Ofek and Richardson (2003), Reed (2002), Ofek, Richardson, and Whitelaw (2003), Mitchell, Pulvino, and Stafford (2002)) to investigate if short-sale constraints contribute to short-term over-reaction in stock prices, and if short sellers are informed. The general conclusion reached by this literature is that short-sale costs are higher and short-sale constraints are more binding among stocks with low market capitalization and stocks with low institutional ownership. The literature also finds that high shorting demand predicts abnormally low future returns both at the weekly and monthly frequency. To our knowledge, no one has examined whether short-sellers are contrarian or momentum traders.

Our data has several advantages compared to the previous literature. We are able to distinguish short-selling by investors who are subject to short-sale rules from market makers that are exempt. Our study focuses on short-selling by non-exempt traders. This is important since market makers will tend to be contrarian investors due to their role as intermediaries. We can identify trade size, and hence can use the dollar size of trades to proxy for short-selling by institutional investors. Moreover, the data allows us to study daily (and even intradaily) shorting activity. Hence, we can capture patterns of short-selling which would never appear in the monthly short interest data. The main drawback with the data is that we cannot capture the ultimate covering of short-sale trades.

We find a tremendous amount of short-selling in our sample. Short-sales represent on average 26.7 percent of Nasdaq reported share volume. By comparison, average monthly short interest for the same period is about 3.1 percent of shares outstanding (5.5 days to cover). Hence, we conjecture that the high fraction of short-sales in daily volume is caused by short-term trading strategies. This extensive amount of short-term short-sale strategies cannot be explained by the activities of equity and options market makers (exempt from short-sale rules). Short-selling by exempt traders represents only 7.8 percent of reported share volume, leaving the remaining 18.9 percent to traders subject to short-sale rules.

The question then becomes, how do Nasdaq short-sellers trade? Do they "pile on" after poor returns as the critics would have it, or do they act contrarian (i.e., sell when they observe a shortterm over-reaction)? Based on our sample, there is no evidence of short-sellers systematically "piling on." In fact, short-sellers actually decrease their shorting activity following negative abnormal returns. Instead, we find strong evidence that short-sellers are contrarian; they increase their short-selling activity following positive abnormal returns. 
We are also interested in finding out whether short-sellers time their trades well relative to future returns (i.e., does short-selling intensify on days preceding negative abnormal returns)? The results show that short-sellers time their trades well relative to short-term price trends. Stock prices decline significantly the day following increased short-selling activity. In fact, increased shortselling is followed by negative returns up to five days out. Hence, there is at least potential for these short-term, short-selling strategies to be profitable. However, absent the data on the ultimate covering of short-sales, we cannot verify when the short-sellers close out their positions.

The lack of information about short-covering transactions in the data means that we cannot calculate trading profits. However, we are able to examine whether it is possible to create a profitable trading strategy based on the daily short-selling activity. We form a portfolio that is long stocks with low short-selling activity and short stocks with a high activity. We find that this long-short portfolio generates significant average returns of 2.6 percent per month when the hold period is one-day and significant average returns of 2.9 percent per month when the holding period is fivedays. Note, however, that trading costs are likely to be substantial because of the short holding periods.

Our data includes information about trade-size, and we follow the previous literature by using trade-size to proxy for trader type. We divide our sample into small, medium, and large short-sales and explore if short-sellers using different sized trades employ systematically different trading strategies with respect to past returns. There is strong evidence of contrarian short-selling activity in both the large and medium trade sizes. We attribute these short-sales to institutional traders. For small trades, there is very strong evidence that short-selling activity decreases significantly following price declines (contrarian trading), but we find no significant change in shorting activity following price increases. The most likely explanation for this pattern is that there is a mix of momentum and contrarian traders in the small trade size. It is unclear why institutional traders would use systematically different strategies when executing short-sales of different size. Thus we conjecture that a significant fraction of retail traders are (negative) momentum traders.

The block-trading literature finds that prices move in the direction of large trades, and these traders are typically associated with institutional trading (e.g., Kraus and Stoll (1972) and Holthausen, Leftwich, and Mayers (1990)). By contrast, the stealth trading hypothesis (Barclay and Warner (1993)) and the order-splitting hypothesis (Bernhard and Hughson (1997)) suggests 
that small or medium-sized trades should be more informative. When it comes to Nasdaq shortsales, we find that it is primarily small trades that are informative, i.e., they predict future negative returns. Recall that we expect that both retail and institutional short-sellers are active in the small short-sale category. By contrast, there is no evidence of a similar ability to predict short-term returns among traders using medium and large short-sales, what we conjecture to be institutional traders.

We consistently find that the link between small-sized trades and future returns is the strongest. For example, a long-short portfolio that is long stocks with low short-selling activity and short stocks with a high activity generates a significant average return of 3.0 percent per month. By contrast, a long-short portfolio based on daily large-sized short-selling activity generates negative and insignificant returns of 16 basis points per month. Our results may seem inconsistent with conventional wisdom that it is institutional traders that are most likely to be informed, and that institutional traders tend to use large orders. This is for instance what Boehmer, Jones, and Zhang (2005) find in a study of short-selling on the NYSE. The key difference between their study and ours is that we study trades and they study orders. An order, particularly if it is large, will tend to get multiple fills. To verify that our results are not simply due to differences between Nasdaq and the NYSE, we replicate our study for NYSE-listed stocks and we find the same patterns. NYSE short-sellers are contrarian, and the predictive link between short-selling and future returns is strongest for small-sized short-sales.

Our sample covers a very large cross-section of stocks, and we know from previous research that short-selling activity and short-sale costs vary systematically in the cross-section. For example, short-sale costs tend to be lower for large stocks and stocks with high institutional ownership (see D'Avolio (2002) and Cohen et al (2005)). To examine whether our results are driven by short-sales in a particular category of stocks, we sub-sample by market capitalization, book-tomarket, institutional ownership, and whether or not the stock has actively traded put options (a potential substitute for short-selling). We find that short-sellers are strongly contrarian in all the sub-samples. They decrease their short-selling activity following negative abnormal returns and increase their short-selling activity following positive abnormal returns. Additionally, we also find that the link between short-selling activity and future returns is significant for small-cap stocks, value stocks, stocks with low institutional ownership, and stocks with no put options. 
Taken together, our results show that short-sellers are not the villains they are made out to be by the media and issuers. They definitely do not "pile on" after poor returns. Instead, traders executing short-sales actually reduce the amount of short-selling significantly following negative abnormal returns. Contrary to public perception, short-sellers increase their activity following positive abnormal returns, and they do so immediately preceding reversals (negative abnormal returns). Hence, the evidence is inconsistent with short-sellers exacerbating stock price downturns.

Our study proceeds as follows. We summarize our hypotheses in Section I, and describe the data in Section II. We test whether short-sellers are primarily contrarian or momentum investors in section III. We address whether short-selling activity predicts future returns, and if contrarian short-sellers are more successful than short-sellers following momentum strategies in Section IV. A number of robustness checks are conducted in Section V. Section VI concludes.

\section{Hypotheses}

Our hypotheses can be summarized as follows:

- If short-sellers are momentum traders, they should increase their short-selling activity following negative abnormal returns. If, on the other hand, short-sellers are contrarian traders, they should increase their short-selling activity following positive abnormal returns.

- If short-sellers can predict future returns, an increase in short-selling activity should predict negative abnormal returns and it should be possible to create a profitable long-short portfolio based on measures of short-selling activity.

We test these hypotheses in the rest of the paper.

\section{Characteristics of short-selling on Nasdaq}

A short-sale is generally a sale of a security by an investor that does not own the security. To deliver the security to the buyer, the short-seller borrows the security and is charged interest for the loan of the security (the loan fee). The rate charged can vary dramatically across stocks depending on loan supply and demand. For example, easy to borrow stocks may have loan fees as low as 
0.05 percent per annum, but some hard-to-borrow stocks have loan fees greater than 10 percent per annum (Cohen, Diether, and Malloy (2005)). If the security price falls (rises), the short-seller will make a profit (loss) when covering the short position by buying the security in the market.

The SEC requires an investor to follow specific rules when executing a short-sale. The rules are aimed at reducing the chances that short-selling will put downward pressure on stock prices. Until May 2, 2005, these rules were different for Exchange-Listed Securities (the tick-test, Rule 10a-1 and 10a-2, NYSE Rule 440B) and Nasdaq National Market (NM) Securities (the best-bid test, NASD Rule 3350). Moreover, Nasdaq NM stocks that were traded on other venues (ECNs) had no bid-test restriction. On June 23, 2004, the SEC adopted Regulation SHO to establish uniform locate and delivery requirements, create uniform marking requirements for sales of all equity securities, and to establish a procedure to temporarily suspend the price-tests for a set of pilot securities during the period May 2, 2005 to April 28, 2006 in order to examine the effectiveness and necessity of short-sale price-tests. At the same time, the SEC mandates that all Self Regulatory Organizations (SROs) make tick-data on short-sales publicly available starting January 2, 2005. The SHO-mandated data includes the ticker, price, volume, time, listing market, and trader type (exempt or non-exempt from short-sale rules) for all short-sales. However, it does not include information about subsequent covering of short-sales (i.e., purchases). In this study, we do not examine the effects of Regulation SHO per se. However, our study is made possible by the SEC mandated short-sale data. In related work, we study the effects of suspending the price-tests on market quality (Diether, Lee, and Werner (2005a)) and how the new delivery and locate requirements affect short-sales and returns (Diether, Lee, and Werner (2005b)).

This study focuses on Nasdaq-listed stocks. ${ }^{3}$ We define the universe of Nasdaq-listed stocks based on all stocks that appear in CRSP with exchange code 3 or 33 (Nasdaq-listed) and share code 10 or 11 (common stocks) at the end of 2004. We draw daily data on returns, prices, and trading volume for these securities from CRSP. We also download intraday data from all SROs that report short-sales for Nasdaq-listed securities and calculate daily short-selling measures. Specifically, we compute the number of trades and shares, classified by whether or not the trader is exempt from short-sale rules and by dollar trade size. We merge the daily short-sale data with return and volume data from CRSP. We then filter the sample by only including common stocks with an end of year

\footnotetext{
${ }^{3}$ See Boehmer, Jones, and Zhang (2005) for a study that focuses on NYSE listed stocks.
} 
2004 price greater than or equal to $\$ 1$. We also exclude stock-days where there is zero volume reported by $\mathrm{CRSP}^{4}$

In addition, we obtain monthly short interest data from Nasdaq, and year-end 2004 data on market capitalization, book-to-market, and average daily trading volume (share turnover) for 2004 from CRSP and COMPUSTAT. We obtain institutional ownership data as of the fourth quarter of 2004 from Thompson Financial (13-F filings), and option trading volume data from The Options Clearing Corporation (www.optionsclearing.com). Our final sample covers trading in 2,815 Nasdaq-listed stocks during the first six months of 2005. To conform with the previous literature, we perform most of our analysis on the stocks with a lagged price of at least $\$ 5.00$ (on average about 1800 stocks per day, but conduct robustness test using the sample of low-priced stocks.

Table I illustrates the distribution of shorted shares in Panel A, and the number of shorted shares in Panel B by market venue: American Stock Exchange (AMEX), Archipelago (ARCAEX), Boston Stock Exchange (BSE), Chicago Stock Exchange (CHX), National Association of Securities Dealers (NASD), ${ }^{5}$ NASDAQ, National Stock Exchange (NSX), ${ }^{6}$ and Philadelphia Stock Exchange (PHLX). NASDAQ accounts for just over half the shares sold short, while ARCAEX and NSX each account for roughly one-quarter. The distribution of shorted shares mirrors the distribution of overall trading volume in Nasdaq-listed stocks across market venues. ${ }^{7}$ Panel A also shows that short-sale trades are much more evenly distributed across the three venues, indicating that short-sales printed on Nasdaq are significantly larger than short-sales printed on other venues.

Panels B and C of Table I provide descriptive statistics for our daily short-selling data covering 2,815 Nasdaq-listed stocks. The average (median) number of shares sold short per day and stock is $205,330(17,180)$ and there are on average (median) 533 (70) short-sales per stock and day. Note that the dispersion across stock-days is significant. To normalize across stocks, we define the relative amount of short-selling (relss) as the daily number of shares sold short for a stock-day divided by the total number of shares traded in the stock during the same day. Overall, shortselling represents an astonishing 26.69 percent of Nasdaq share volume. Hence, over one in four

\footnotetext{
${ }^{4} \mathrm{We}$ also set short-sales equal to volume in the few instances where short-sales exceed reported volume. Our results are robust to excluding these stock-days from our analysis.

${ }^{5}$ NASD operates the Alternative Display Facility (ADF), where trades may be printed.

${ }^{6}$ Formerly known as the Cincinnati Stock Exchange.

${ }^{7}$ In may 2005, Nasdaq traded 55.8 percent of share volume, Archipelago traded 18.2 percent, and NSX traded 24.8 percent (source: www.nasdaq.com).
} 
shares traded on Nasdaq involves a short-seller. This is eight times more short-selling than what was found by Christophe, Ferri, and Angel (2004) based on a three month period in $2000 .^{8}$ By comparison, monthly short-interest, defined as the number of shorted shares divided by average daily share volume, is 5.48 during our sample period (see Table II).

In other words, for the average stock, it would take a more than five days to cover the short position if short-selling was 100 percent of volume. Or, conversely, starting from zero short shares outstanding, the average short position can be created in about one month ( 20 trading days) at the rate of short-selling in our sample, provided that no covering takes place during the period (20 $\mathrm{x} 0.27=4.54$ ). As a practical matter, short-positions are obviously not created over a one month period. Instead, many short-sales that are likely based on short-term patterns in stock prices would not necessarily be captured by changes in monthly short interest data. Recall that while we do not observe the covering activity, we know that it has to be of the same order of magnitude as the short-selling since the month to month changes in average short interest in our sample is relatively minor (2.7-3.4 percent of shares outstanding).

Clearly, short-sellers have flourished during the stock market decline of the first half of this decade. We conjecture that this increase in short-selling activity can be explained by a number of factors: increased pessimism among investors following the bubble bursting in March 2000, increased use of algorithmic trading, and the tremendous growth of the hedge fund industry which employs long-short strategies.

In Panel $\mathrm{C}$ of Table I, we also divide short-selling activity among traders that are exempt from short-sale rules (equity and options market makers) from those that are not (regular traders). We find that short-selling by traders subject to the short-sale rules represent 18.93 percent of daily share volume on average, while the exempt traders represent 7.77 percent.

We would like to use trade-size to proxy for institutional trading. The challenge we face is the extensive amount of order-splitting in todays' trading environment. The average trade size on Nasdaq has shrunk precipitously after decimalization, and it is now roughly 400 shares. What used to be considered an institutional trade (10,000 shares and above) represents less than a quarter of one percent of all trades and about 16 percent of share volume. ${ }^{9}$ Clearly, institutions do not only

\footnotetext{
${ }^{8}$ In a recent paper, Boehmer, Jones and Zhang (2005) find short-selling based on system orders for NYSE stocks to be 14.3 percent of reported volume.

${ }^{9}$ www.nasdaqtrader.com
} 
trade in traditional blocks anymore.

We use the actual short-sale size distribution within our sample to define the size cutoffs. The distribution has roughly 50 percent of trades less than or equal to $\$ 4,400$ (200 shares); roughly 45 percent between $\$ 4,400$ (200 shares) and $\$ 37,000$ (1,500 shares), and roughly 5 percent above $\$ 37,000$ (1,500 shares). Hence, we define small short sales as those trades that are less than or equal to $\$ 4,400$, medium short-sales as those trades that are larger than $\$ 4,400$ but less than or equal to $\$ 37,000$, and big short-sales as those trades that are larger than $\$ 37,000$. We hope to capture primarily institutional trades in the large size category, but due to order-splitting we are bound to have both retail and institutional traders in the small-size, and perhaps even the mediumsize category. ${ }^{10}$

Table I shows that 12.00 percent of average daily volume are small short-sales, 10.52 percent are medium short-sales, and 4.17 percent are large short-sales. When broken out by whether or not the trader is subject to short-sale rules, we find that exempt traders are more likely to sell short in large trades than non-exempt ones. This is not surprising since these traders are equity or options market makers. Short-sales for market makers will to a large extent be dictated by their role as intermediaries, and as such they will tend to be contrarian. In the analysis that follows, we will focus on short-sales by traders that are subject to the short-sale rules, and have no easily identifiable exogenous reason for being contrarian traders. In other words, we only study non-exempt shortsales.

The last panel of Table I reports how average short-selling activity varies by firm characteristics. We define size (ME) and book-to-market (B/M) terciles based on NYSE breakpoints, and find that large-cap stocks and low book-to-market stocks (growth stocks) have greater short-selling on average than small-cap stocks and value stocks. Stocks with high institutional ownership at the end of 2004 and stocks with high trading volume (share turnover) during 2004 (CRSP) have greater short-selling activity than stocks with low institutional ownership and low trading volume. We also find that stocks with a price at or above $\$ 5.00$ have more short-selling than those with prices below $\$ 5.00$. Buying put options is an alternative way to make a negative bet on a stock, but stocks with actively traded puts (www.optionsclearing.com) have higher short-selling activity. This is not very surprising since stocks with actively traded puts are also likely to be larger more liquid stocks.

\footnotetext{
${ }^{10}$ We have varied the breakpoints and find very similar results.
} 
For completeness, we also calculate statistics for two sub-samples by price (not reported): stocks with a year-end 2004 price less than \$5.00 (543 stocks), and stocks with a year-end price at $\$ 5.00$ and above $(2,278)$. Short-sales represent a larger fraction of average daily share volume (27.77 percent) for higher priced stocks than for lower priced stocks (13.90 percent).

In Table II, we summarize cross-sectional information on short-sales as well as stock characteristics. Panel A is constructed from the average daily short-sales for each stock. The cross-sectional average relss is very close to the stock-day average in Table I, and average short-selling activity varies from 0 percent to 43 percent of daily share volume in the sample. The average (median) stock has a market capitalization of \$1,091.0 (\$201.7) million as of year-end 2004, and marketcap ranges from $\$ 2.8$ million to $\$ 290.3$ billion. The average (median) stock has a book-to-market $(\mathrm{B} / \mathrm{M})$ of $0.54(0.45)$, and the average (median) institutional ownership is 40 (35) percent of shares outstanding. We also have information on short positions, and for comparison with relss we relate this figure to average daily volume. Short positions would take 5.48 (3.49) days to cover if all trades were short-sales on average (median). Note that there are some extreme short positions within the sample - the maximum value is 316.32 days to cover, or roughly 60 weeks (15 months). The average (median) price of sample stocks is $\$ 18.30$ (\$14.03) and the average (median) turnover is $0.88(0.48)$ percent. Finally, one third of stocks in our sample have actively traded put options.

Panel B of Table II reports the cross-sectional correlations between our short-sale measures and stock-characteristics. All three measures of short-selling activity are significantly positively correlated with size, institutional ownership, short-positions, price, turnover, and a dummy for actively traded put options. By contrast, short-selling activity is significantly negatively correlated to B/M. Hence, growth stocks have more short-selling activity than value stocks.

\section{How do short-sellers react to past returns?}

What signals do traders use to decide when to short a stock? While providing a complete answer to this question is beyond the scope of our paper, it is reasonable to assume that short-sellers rely heavily on past price-patterns. The major reason for this conjecture is that virtually every book on short-selling uses price-pattern-based technical trading rules as entry and exit signals. Consequently, we analyze how short-sellers react to past abnormal returns. Our study focuses on short-term, short-selling strategies. Therefore, we chose a five-day window preceding the day of 
the short-sale as our period to measure abnormal returns. As described in the hypothesis section, we will first test if short-sellers are momentum or contrarian traders. Recall that momentum traders are expected to increase their short-sales following negative returns, while contrarian traders are expected to increase short-sales following positive returns.

In table III we regress individual stock short-sales during day $t$ ( relss $_{t}$ ) on past returns. The panel regressions include day and stock fixed effects, and standard errors corrected for clustering by calendar date. ${ }^{11}$ Additionally, the regressions only include stocks with lagged price greater than or equal to $\$ 5$. It is clear from the first column that short-selling activity increases significantly in past market adjusted returns, ret $_{-5,-1}$. The coefficient implies that an abnormal return over the past five days of 10 percent results in an increase in short-selling of $1.70 \%$ of average daily share volume. Hence, short-sellers are contrarian on average. Including lagged short-sales ( relss $\left._{t-1}\right)$ weakens the magnitude of the effect (column two), but it is still highly significant.

We explore asymmetric responses to past returns in column three by separating past returns into positive market adjusted returns, $r_{-5,-1}^{+}$, and the absolute value of negative market adjusted returns, $r_{-5,-1}^{-}$(if the abnormal return is negative (positive) then $r_{-5,-1}^{+}\left(r_{-5,-1}^{-}\right)$equals zero). Short-selling is significantly higher following positive returns, and significantly lower after negative returns. The magnitude of the coefficient on negative returns is four times as large and highly significant. This can be explained by the "asymmetry" of returns. ${ }^{12}$ An abnormal negative return of 10 percent during the past five days is associated with a reduction in short-selling corresponding to 2.72 percent of average daily trading volume. Hence, there is strong evidence that traders short less following stock price declines. These results are robust to controlling for the previous day's shortselling activity. This reinforces our result that short-sellers are contrarian, and not momentum traders, on average.

The rest of the columns of Table III report the results for regressions involving each short-sale size-grouping: small, medium, and large. Small-sized short-selling activity decreases following positive abnormal returns, but the effect is small in magnitude and not statistically significant. Furthermore, the traders using small-sized shorts are not momentum traders in the traditional sense

\footnotetext{
${ }^{11}$ The results are qualitatively the same if we use firm characteristics instead of stock fixed effects.

${ }^{12}$ For example, compare the return on a (very volatile) stock that moves from $\$ 2.00$ to $\$ 6.00$ one week and from $\$ 6.00$ to $\$ 2.00$ another week. The returns would be 400 percent and -75 percent respectively. In our sample, the largest positive five-day returns are almost 300 percent while the largest negative five-day returns are roughly 60 percent.
} 
since they actually reduce their short-selling activity significantly following negative abnormal returns. In other words, they act contrarian after price declines. Medium and large-sized shortsales are contrarian on average, and also when past returns are broken up into positive and negative returns. All the results are robust to including the previous day's short-selling activity.

Note also that the magnitude of the coefficients actually tend to decline with trade size (the exception being small-sized shorts after positive returns). For example, a 10 percent decrease in abnormal returns is associated with a decrease in small short-sales of 1.41 percent, in medium short-sale of 1.04 percent, and of large short sales of 0.27 percent. This is to be expected since the timing of medium and large size short-sales is likely to be relatively more dependent on the available liquidity.

Recall that institutions are likely to be responsible for virtually all trades in the large category, and most trades in the medium category. Hence, the evidence shows that institutional short-sellers are contrarian. Since it is unclear why institutions would pursue a significantly different trading strategy when trading in the small-size category, we conjecture that it is momentum trading by retail traders that weakens the coefficient on past positive abnormal returns for the small-size category.

\section{Can short-sellers predict future returns?}

Having established that short-sellers are contrarian on average during our sample period, we now test whether they are able to predict future abnormal returns. For the shorting strategy to be successful, the stock price has to decline in the future so that the short-seller can cover his position and still make profits large enough to cover trading costs and short-selling costs.

The problem is that we cannot observe the actual covering transactions. We do not know whether short-sellers keep their positions open for one day, a week, a month, or even several months. We are also restricted in that our sample period is short, only six months. To be very conservative, we start by examining if a significant increase in today's short-selling activity is associated with a significant negative abnormal return tomorrow. The short window for measuring short-selling activity (one day) and the short horizon (one day) will make it very difficult to find predictive power.

Table IV reports the results of panel regressions with day fixed effects and standard errors 
corrected for clustering by calendar date. We regress returns on day $t+1$ on relss for day $t .{ }^{13}$ The regressions only include stocks with lagged price greater than or equal to $\$ 5$. Since previous research (Fama and French (1992)) has pointed out that size and book-to-market help explain the cross-section of average returns (and may proxy for risk factors) we control for size $(\log (M E)$ ) and book-to-market, $(\log (B / M))$ on the right hand side. Note that in our short sample period, only book-to-market is significantly related to future returns. ${ }^{14}$ In addition, we add day $t$ marketadjusted returns $\left(r_{t}\right)$ as an independent variable to control for reversals that are present in the daily return data during our sample.

In the first column of Table IV, we report the results of regressing future returns on (nonexempt) short-sales as a fraction of average daily volume, relss. Clearly, higher short-selling today predicts a future decline in abnormal returns. The economic magnitude of the effect is also significant - a one standard deviation increase in relss predicts a 2.90 basis point decline in next day abnormal returns which corresponds to an annualized compounded return of 7.52 percent. ${ }^{15}$

One concern may be that there is significant positive autocorrelation in short-sale activity, which may itself cause prices to decline on day $t+1$. It turns out that while short-sales are positively correlated in our sample, the effect does not eliminate the predictive ability of today's short-sales. Acknowledging that column two is not a predictive regression, we experiment by including the next day's short-sales on the right hand side. The results show that if short-sales are high tomorrow, returns are actually significantly higher. Once we control for this pattern, higher short-sales today are associated with a larger (54.3 percent per year) and much more significant negative return. The reason for these results is that short-sellers are contrarian on average. Hence, they sell following positive abnormal returns. Putting future short-sales in the regression helps separate days when short-sellers are still building a position (positive future returns) from the days when short-sellers reduce their activity (negative future returns).

We control for past abnormal returns in column three, but the effect is not significant after we control for short-sales and daily return reversals. We refine the tests in columns four to six by splitting up the past abnormal returns by sign and interacting the signed past returns with short-

\footnotetext{
${ }^{13}$ We have also run these regressions using the Fama-MacBeth (1973) methodology with Newey-West (1987) correct standard errors, and the results are very similar.

${ }^{14}$ Value stocks did better than growth stocks during our sample period. For example, the average monthly return on HML, the Value-Growth factor (Fama and French (1993)), is 1.33\% during our sample period.

${ }^{15}$ Calculated as $(1.000290)^{250}-1$.
} 
selling. This weakens the direct effect of short-sales on future abnormal returns, and the results show that there is no significant difference between momentum and contrarian short-sellers on average in predicting future abnormal returns.

As mentioned above, we do not know the short-sellers' horizon. It is most likely longer than one day. Therefore, we also test whether today's short-sales predict the returns one, two, three, four, and five days out. Figure 1 plots the coefficient estimates on relss as well as the corrected t-statistics. The underlying regression specification is the same as in the first column of Table IV. Short-sales predict negative returns up to five days out, but the significance declines over time.

Previously, we saw that there were significant differences in short-selling strategies between the traders that use small short-sales and the traders that use medium and large short-sales. Do these groups of investors also have different abilities in predicting future stock returns? Column seven of Table IV clearly shows that it is the small short-sales that predict future abnormal negative returns. The effect is also economically significant, with a one standard deviation increase in smallsized short-sales resulting in an increase in the next day abnormal return of 4.74 basis points, or an annualized return of 12.57 percent.

Are the small short-sales simply "free-riding" on reversals or momentum? To address this question, we control for past abnormal returns in the last two columns of Table IV. The second to the last column shows that contrarian trading (high short-selling when past abnormal returns are positive) by small-sized short-sales significantly predicts future negative returns. What about the momentum traders? The final column shows that they are fighting against an overall pattern of return-reversals in the data. This pattern can be exploited by contrarian traders, but works against the strategy of momentum traders. Once we control for the return-reversals, the last column shows that small momentum short-sales predict negative future abnormal returns. In other words, in the instances when short-sellers trade on momentum, they are able to time their trades to the days when there are continuations in returns.

The second panel of Figure 1 shows the ability of small short-sales in predicting returns one, two, three, four, and five days out. The effect of today's short-sales is consistently negative, and it is statistically significant on day one. The coefficients are uniformly bigger than when we use all short-selling trades (see the first panel).

If returns are predictable, it is at least potentially possible to develop a profitable trading strat- 
egy based on the information in the Reg SHO short-sale data. To investigate this, we first compute relss, relss small, and relss $s_{\text {big }}$ quintiles using all stocks in our sample on date $t$. We form portfolios on day $t$ using all stocks in our sample with a closing price on day $t-1$ greater than or equal to $\$ 5.00$. We then calculate the market-adjusted (abnormal) returns on day +1 for all the portfolios. The portfolios are rebalanced daily. ${ }^{16}$

Table V summarizes the results. First note that abnormal returns tend to decline in short-selling as a fraction of trading volume (Panel A). The last column provides the difference in returns between the low and high relss portfolios in percent. ${ }^{17}$ A strategy of going long the low relss portfolio and short the high relss portfolio (Low-High) generates a statistically significant daily average return of 0.128 percent (2.6 percent per month). If we extend the holding period to five days using the overlapping holding period methodology of Jegadeesh and Titman (1993), the results are even stronger with a statistically significant average daily return of 0.144 percent $(2.9$ percent per month).

For small short-sales (Panel B), abnormal returns are monotonically declining in relss. Trading based on small short-sales generates a slightly higher average return of 0.149 percent per day (3.0 percent per month). Also in this case, the results are strengthened for the five-day holding period with a statistically significant average return to the Low-High strategy of 0.166 percent per day (3.4 percent per month).

We examine long-short portfolios based on large short-sales in Panel C. The long-short strategy based on large short-sales generates returns that are insignificantly different from zero both for the one-day and the five-day holding periods.

The average return on Low-High strategy may seem "too large," but execution costs and commissions are likely to be significant because of daily rebalancing. Moreover, we need to take the cost of shorting into account. To gauge the importance of trading costs, let us assume that one quarter of the stocks in the portfolio are turned over daily. Based on SEC mandated 11Ac1-5 reports for all market centers reporting execution quality for Nasdaq-listed stocks, ${ }^{18}$ we estimate the

\footnotetext{
${ }^{16}$ The results are very similar if we instead compute size and book-to-market adjusted returns based on the standard 25 equally-weighted portfolios (Fama and French (1993)). For example, the average return of Low-High portfolio is 0.128 percent per day $(\mathrm{t}-\mathrm{stat}=3.31)$, and the size-B/M average abnormal return of the same portfolio is 0.114 percent (t-stat=4.132).

${ }^{17}$ Two-thirds to three-quarters of the stocks in the low relss portfolio have zero short-sales for the day of portfolio formation.

${ }^{18}$ We downloaded the regulatory data from the web-sites of: Archipelago, Island, Instinet, Madoff, NSX, Nasdaq,
} 
average effective spread of our portfolio by finding the average effective share-weighted spread for stocks in March of 2005 with similar market-cap as the average of the Low-High portfolio. Our estimate of the effective spread is 62 basis points. Thus execution costs for the Low-High portfolio would be roughly 6.2 percent per month (not including commissions). By comparison, explicit costs of shorting are relatively small. Cohen, Diether, and Malloy (2005), estimate these costs to be 3.98 percent per year (32.6 basis points per month) for stocks with market capitalization below the NYSE median. Thus, unless a trader managed her costs very effectively (maybe through the use of limit orders), she could easily wipe out the positive return from a Low-High portfolio strategy.

\section{Robustness tests: Cross-sectional differences in short-selling}

It is quite likely that the relationship between short-selling and past returns, as well as the ability of short-sellers to time their trades before negative returns varies significantly in the cross-section. For example, since we know from the previous literature that it is easier to sell short in larger firms, in more liquid firms, and in firms with higher institutional ownership, it is likely that short-selling is more sensitive to past returns for these stocks.

We sort the stocks into terciles based on CRSP market capitalization as of year-end 2004. The breakpoints are determined by NYSE stocks. We contrast the effect of past returns on shortselling for small-cap and large-cap stocks in Panel A of Table VI. The overall contrarian pattern of short-sales is present and significant both for small-cap and large-cap stocks. As expected, the magnitude of the coefficient on relss is more than twice as large for large-cap stocks compared to small-cap stocks. Clearly, it is easier (and cheaper) for short-sellers to establish a short position in large-cap stocks all else equal. Traders using medium- and large-sized trades are contrarian for all sub-samples (not reported). Traders using small short-sales are contrarian following negative abnormal returns, but they do not change their short-selling activity significantly following positive abnormal returns.

The previous literature has tested and confirmed the Miller (1977) hypothesis that short-selling demand seems higher for low growth stocks than it is for value stocks (Jones and Lamont (2002)). We divide our sample into growth stocks (lowest B/M tercile) and value stocks (highest B/M terKnight, and Trimark. 
cile) based on NYSE breakpoints. Table VI Panel B reports the results. There is a strong contrarian pattern both in growth and value stocks, and as expected the magnitude and significance of the coefficient on relss is higher for growth than for value stocks. Small-sized short-sellers are contrarian following negative abnormal returns, but they do not respond significantly to positive abnormal returns for value stocks and actually reduce their short-sales significantly following positive abnormal returns. Medium and large-sized traders are consistently contrarian (not reported).

The previous literature has shown that stocks with high institutional ownership are less costly to short, all else equal (D'Avolio (2002)). The suggested reason for this in the literature is that institutions are more likely to be willing to lend stock. Hence, we divide the sample based on institutional ownership to examine if our results are driven by stocks with high institutional ownership. The results are in Panel C of Table VI. We find that short-sellers are contrarian both in stocks with high and low institutional ownership, but as expected, the magnitude of the effect of past abnormal returns on future short-sales is almost three times as high for stocks with high institutional ownership. Traders using small-size trades are contrarian following negative returns but do not respond significantly to positive abnormal returns, while those using medium- and large-sized trades are consistently contrarian.

Several authors (Brent, Morse, and Stice (1990), Danielsen and Sorescu (2001), Chen and Singal (2003), and Senchak and Starks (1993)) have explored the interaction between the options market and the stock market to investigate the extent to which short-sale constraints are binding. A trader that wants to express a negative view about a security can either sell the security if he happens to own it, sell the security short, or buy at the money put options. So, for stocks with actively traded put options, there are more alternatives to bet on a decline in stock prices. ${ }^{19}$ Therefore, we conjecture that short-selling should be less sensitive to past returns for stocks with actively traded put options. To test this hypothesis, we download daily put option trading volume from the Options Clearing Corporation (www.optionsclearing.com), and divide the sample into stocks with and without traded put options. ${ }^{20}$ Panel D of Table VI reports the results. Whether or not a stock has put options, traders are strongly contrarian on average. Both subsamples display contrarian trading after negative abnormal returns and no significant effect of positive abnormal returns by

\footnotetext{
${ }^{19}$ In addition, they could use single stock futures. However, these are relatively illiquid.

${ }^{20}$ Note that there could be significant OTC trading in put options for securities where there is no activity on the options exchanges, which will reduce our chances of finding a significant result.
} 
short-sellers using small trades, while medium and institutional-size short-sales are consistently contrarian.

We also repeat the panel regressions of future returns on current short-sales and other control variables that we conducted for the overall sample (Table IV) for the sub-samples by size, bookto-market, institutional ownership, and put option activity. However, in the interest of brevity, we only report the estimated coefficients and the associated t-statistics for relss and relss $s_{\text {small }}$ on future abnormal returns in graphical form in Figures 2 to $5 .^{21}$ These estimates come from the predictive regressions for one through five days ahead (see Figure 1).

In Figure 2 we show that higher short-selling predicts consistently negative future abnormal returns for both small-cap and large-cap stocks. For small-cap stocks, the predictability is only significant on day one, but for large-cap stocks it is significant on day one, two, and three. The

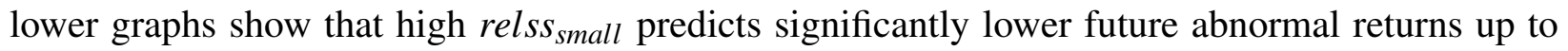
four days ahead for small-cap stocks, but the effect is insignificant for large-cap stocks. Note also that the magnitude of the coefficients tends to be larger for relss small than for overall relss. We also repeat this exercise, contrasting low and high-liquidity stocks (not reported), and find that the patterns are very similar to the ones just described for small-cap versus large-cap stocks.

Figure 3 shows that for growth stocks, we have consistently negative coefficients but they are not significant. The pattern for value stocks is more puzzling, with an oscillating coefficient. ${ }^{22}$ Note, however, that the negative coefficient is significant one and three days out, and the days in between do not eliminate the cumulative effect of relss on future returns. As before, relss small is a better predictor of future abnormal returns, and the magnitude of the coefficients is larger. relss small is a significant predictor of future abnormal returns one day ahead for growth stocks, and one and three and days ahead for value stocks.

Figure 4 shows that short-selling among stocks with low institutional ownership is negatively related to future returns throughout the five day window, but the coefficients are not significant on days two through five. For stocks with high institutional ownership, the relationship is negative but only significant on day four. The estimated coefficient on relss $_{\text {small }}$ is larger in magnitude for both sub-samples, and it is also significant for stocks with high institutional ownership (one and three

\footnotetext{
${ }^{21}$ The complete results are available from the authors on request.

${ }^{22}$ Recall that we already control for the previous day's abnormal return. However, this may not be sufficient to eliminate bid-ask bounce. We redid the analysis based on mid-quote returns, but the oscillating patter remains.
} 
days out).

Figure 5 shows that short-selling among stocks without puts is significantly related to future returns for the one-day horizon, and for stocks with puts only the four day ahead forecast is significant. For relss small, we only find significant predictability for stocks without actively traded put options (one, three and four days out).

The panel regressions behind Figures 2 through 5 assume a specific functional form for the relationship between current short-sales and future abnormal returns. A more general way to test for whether short-sellers have information is to form portfolios based on the level of short-selling activity. We thus repeat the exercise from Table V for our subsamples. That is, we first sort stocks into terciles by characteristics (size, book-to-market, institutional ownership) and into those with and without actively traded puts. We also sort stocks into relss and relss small $_{\text {quintiles every trading }}$ day. We then form double-sort portfolios based on the intersection of these measures on day $t$ and compute the return for the portfolios on day $t+1$. We rebalance the double-sort portfolios daily. Furthermore, we form a long-short portfolio by buying stocks with low short-sale activity, and shorting stocks with high short-sale activity. If there is information in the amount of short-selling, these portfolios should generate positive and significant abnormal returns.

The results of the double-sorts by characteristics and short-sale activity are in Table VII. For brevity, we only report the low and the high portfolios, and the returns to the long-short (Low-High) portfolio. The trading strategy based on relss generates significantly positive profits for small-cap stocks, value stocks, for stocks with low institutional ownership, and for stocks with no put options. These results reinforce the pattern that we found based on the panel regressions. Interestingly, the strategy based on relss $s_{\text {small }}$ generates significantly positive profits for all sub-samples except large-cap stocks and stocks with put options, but the returns to the Low-High portfolio shows that profits are higher in small-cap, value stocks, stocks with low institutional ownership, and stocks with no put options. Hence, the portfolio results once again verify that small-sized short-sales are particularly successful at predicting future abnormal returns.

We also investigate the relationship between short-sales and returns for the stocks in our sample that have lagged price below $\$ 5.00$ (low price stocks). We find that short-sellers are contrarian overall and for each separate trade-size grouping, but that daily short-selling does not significantly predict future returns. 
Finally, we repeat the analysis with trade-size groupings defined in shares instead of dollars. The results are qualitatively the same as those discussed above.

Throughout our study, we find that it is particularly small-sized short-sales that are able to predict future negative returns. Our results may seem inconsistent with conventional wisdom that it is institutional traders that are most likely to be informed, and that institutional traders tend to use large orders. This is for instance what Boehmer, Jones, and Zhang (2005) find in a study of shortselling on the NYSE. They examine whether short-sellers submitting orders to NYSE's SuperDOT are informed about future abnormal returns. We believe that the key difference between their study and ours is that we study trades and they study orders. An order, particularly if it is large, will tend to get multiple fills.

To verify that our results are not simply due to differences between Nasdaq and the NYSE, we repeat our analysis in a condensed form for NYSE-listed stocks during our sample period. We require stocks to have CRSP share code 10 or 11 and with a price greater than or equal to $\$ 1.00$ at the end of year 2004. Stocks are dropped from the sample if the number of traded shares is less than or equal to zero. The final NYSE sample is 1,435 stocks. Panel A of Table VIII summarizes the NYSE short-selling activity. Note that the figures capture short-sales both on the NYSE, and in other venues that execute trades in NYSE-listed stocks (e.g., Nasdaq, ArcaEX, BSE, NSX, PHLX, CHX, NASD, and AMEX). We find that short-sales represent 23.75 percent of consolidated share volume for sample stocks. The vast majority, 22.82 percent, is non-exempt short-sales. These figures are significantly higher than the 13 percent reported by Boehmer et al (2005). The main explanation is probably that Boehmer et al (2005) only include SuperDOT orders in their analysis, and hence misses both floor-initiated orders and off-exchange activity.

Panel B of Table VIII shows that short-sellers in NYSE-listed stocks are also contrarian. The results are strong both for the simple specification, and for the one where we split up returns into positive and negative parts. Short-sellers in NYSE-listed stocks significantly increase their shortselling activity following positive returns, and significantly decreases their short-selling activity following negative returns. When we split the short-sales into groups by size, it appears that smallsized short-sales are contrarian following negative returns, while they actually reduce the amount of short-selling following positive returns. By contrast, medium and large short-sales are consistently contrarian. Note that the magnitude of the coefficients for overall relss are much larger for NYSE- 
listed stocks. With the exception of small-sized short-sales, short-sale activity is more sensitive to past returns for NYSE-listed stocks.

The ability of short-sales in NYSE-listed stocks to predict future returns is illustrated in Table IX. We focus on the portfolio results, and report the results of a portfolio strategy that goes long in stocks with low relss and short in stocks with high relss (mirrors Table V). For total relss in Panel A, we find that this portfolio generates a statistically significant average return of 0.064 (0.067) percent per day for a one-day (five-day) holding period. This translates into a 1.3 (1.3) percent average return per month which is roughly half the size of the return to a similar portfolio strategy for Nasdaq-listed stocks (Table V). Panels B and C repeat the analysis for small-sized and large-sized short-sales. It is clear that it is the small-sized short-sales that are responsible for the overall significant average returns to the long-short strategy based on short-selling activity. Hence, we find that small short-sales are also more informative about future returns on the NYSE. We do not believe that this is inconsistent with the results in Boehmer et al (2005) who find that institutions are better informed since our analysis is based on trades, not on orders.

In summary, we have conducted robustness tests using various sub-samples: market capitalization, liquidity, book-to-market, institutional ownership, whether or not the stock has exchange traded put options, and stock price. No matter how we cut the data, we find strong evidence that short-sellers on average are contrarian traders. The predictive ability of contrarian short-sellers in the aggregate is stronger for small-cap stocks, for less liquid stocks, for value stocks, stocks with low institutional ownership, for stocks without actively traded puts, and for higher priced stocks. It is the traders that use small short-sales that are particularly successful at predicting future abnormal returns. We also examine a sample of NYSE-listed stocks to verify that our results are not specific to Nasdaq-listed securities.

An important caveat should be kept in mind in interpreting these results. Due to the short sample, we are focusing on the success of very short-term predictability of returns. It is possible that traders using medium and large short-sales have a longer horizon, and that their short-sales are predicting future negative returns beyond five days out. 


\section{Conclusions}

Short-sellers definitely have a bad reputation in the media as well as among issuers, and they are often accused of exacerbating stock price declines by trading on negative momentum. However, to date very little evidence has been offered to shed light on whether or not short-sellers "pile on" after poor returns. In fact, we do not know anything about how short-sale transactions are timed relative to past returns, nor do we know if short-sellers time their trades well relative to future (negative) returns. Also, very little is known about short-selling activity at the daily horizon. Our paper attempts to fill these voids.

Overall, we find a tremendous amount of short-selling in our data. On average, short-sales represent 26.7 percent of daily share volume for Nasdaq-listed stocks and 23.75 percent of daily share volume for NYSE-listed stocks. This is considerably higher than what would be suggested by short interest data, as well as previous evidence on short-selling activity (Christophe et al (2004)). We conjecture that this high frequency of short-sales can be explained by increased pessimism, the increased use of algorithmic trading, and the growth in the importance of hedge funds in U.S. financial markets.

Our main focus is to investigate how short-sellers respond to past returns, and if their trades predict future negative abnormal returns. We find strong evidence that short-sellers in Nasdaq-listed stocks are contrarian traders. They increase their short-selling activities after positive abnormal returns, and reduce their short-selling following negative abnormal returns. We also find that increased short-selling activity predicts negative abnormal future returns, in some cases as much as five days out. It is primarily small short-sales that predict future negative returns, and short-sellers using small trades are successful at predicting both continuations and reversals in returns.

We also find that a trading strategy that goes long in stocks with low short-selling activity and sells short stocks with high short-selling activity generates significant positive average returns, but these positive returns could easily be wiped out by trading costs and the cost of shorting.

A number of robustness checks by stock characteristics such as size, book-to-market, institutional ownership, and put-option trading, reveal that while there is universal evidence of contrarian trading for all sub-samples. The results also show that the predictability of short-selling on future abnormal returns is higher for small-cap stocks, for less liquid securities, for value stocks, for stocks with low institutional ownership, and for stocks with no traded put options. Additionally, 
we find in all sub-samples that it is primarily small short-sales that predict future negative returns

Finally, we find very similar results for short-selling activity in NYSE-listed stocks during our sample period. Hence, our findings that short-sellers are contrarian and particularly small-sized short-sales are able to predict returns are not simply a Nasdaq phenomenon.

Our finding are consistent with a recent paper by Avramov, Chordia, and Goyal (2005) who study the impact of trades on daily volatility. They find that increased activity by contrarian traders (identified as sales following price increases) is associated with lower future volatility, while increased activity by herding investors (identified as buyers after price increases) is associated with higher future volatility. Avramov et al (2005) argue that contrarian traders are rational traders that trade to benefit from the deviation of prices from fundamentals. As these trades make prices more informative, they tend to reduce future volatility. We provide more direct evidence of the information content of contrarian short-sellers in that they predict future returns.

Taken together, our results show that short-sellers are not the villains they are made out to be by media and issuers. They definitely do not "pile on" after poor returns. Instead, traders executing short-sales actually reduce the amount of short-selling significantly following negative abnormal returns. Contrary to public perception, short-sellers increase their activity following positive abnormal returns, and they do so immediately preceding reversals (negative abnormal returns). Hence, the evidence is consistent with short-sellers helping correct short-term over-reactions of stock prices. The fact that they are relatively more successful at predicting returns for stocks that are more likely to have pricing errors (small-cap stocks, less liquid stocks, stocks with low institutional ownership, and stocks without put options) is further suggestive evidence that short-sellers may actually help make prices more efficient. 


\section{References}

Angel, J., S. Christophe, and M. Ferri, 2003, A Close Look at Short Selling on Nasdaq, Financial Analysts Journal 59, 66-74.

Asquith, P., P. Pathak, and J. Ritter, 2005, Short Interest, Institutional Ownership, and Stock Returns, Journal of Financial Economics, forthcoming.

Avramov, D., T. Chordia, A. Goyal, 2005, The Impact of Trades on Daily Volatility, forthcoming in the Review of Financial Studies.

Barclay, M., and J. Warner, 1993, Stealth Trading and Volatility: Which Trades Move Prices?, Journal of Financial Economics, 34, 281-305.

Battalio, R., and P. Schultz, 2005, Options and the Bubble, working paper.

Bernhard, D., and E. Hughson, 1997, Splitting Orders, Review of Financial Studies, 10, 69-101.

Boni, L., 2004, Strategic Delivery Failures in the U.S. Equity Markets, working paper.

Boehmer, E., C. Jones, and X. Zhang, 2005, Which Shorts are Informed, working paper, Texas A\&M University.

Brent, A., D. Morse, and K. Stice, 1990, Short interest: Explanations and tests, Journal of Financial and Quantitative Analysis 25, 273-289.

Chakravarty, S., J. Gulen, and S. Mayhew, 2004, Informed Trading in Stock and Option Markets, The Journal of Finance 59, 1235-1257.

Chen, J., H. Hong, and J. Stein, 2002, Breadth of Ownership and Stock Returns, Journal of Financial Economics 66, 171-205.

Chen, H., and V. Singal, 2003, Rise of Speculative Short Sales in Price Formation: The Case of the Weekend Effect, Journal of Finance 58, 685-706.

Christophe, S., M. Ferri, and J. Angel, 2004, Short-Selling Prior to Earnings Announcements, The Journal of Finance 59, 1845-1875. 
Cohen, L., K. Diether, and C. Malloy, 2005, Supply and Demand Shifts in the Shorting Market, Working paper.

Danielsen, B., and S. Sorescu, 2001, Why do Option Introductions Depress Stock Prices? An Empirical Study of Diminishing Short Sale Constraints, Journal of Financial and Quantitative Analysis 36, 451-484.

D’Avolio, G., 2002, The Market for Borrowing Stock, Journal of Financial Economics 66, 271306.

Daske, H., S. Richardson, and I. Tuna, 2005, Do Short Sale Transactions Precede Bad News Events?, working paper, University of Pennsylvania.

Dechow, P., A. Hutton, L. Meulbroek, and R. Sloan, 2001, Short-sellers, Fundamental Analysis and Stock Returns, Journal of Financial Economics 61, 77-106.

Desai, H., K. Ramesh, S. Thiagarajan, and B. Balachandran, 2002, An Investigation of the Information Role of Short Interest in the Nasdaq Market, Journal of Finance 52, 2263-2287.

Diamond, D., and R. Verrecchia, 1987, Constraints on Short-selling and Asset Price Adjustment to Private Information, Journal of Financial Economics 18, 277-311.

Diether, K., C. Malloy, and A. Scherbina, 2002, Differences of Opinion and the CrossSection of Stock Returns, Journal of Finance 57, 2113-2141.

Diether, K., K-H. Lee, and I.M. Werner, 2005, It's SHO Time! Short-sale Price-tests and Market Quality, Working paper, The Ohio State University.

Diether, K., K-H. Lee, and I.M. Werner, 2005, Tightening Short-sale Constraints: The Case of Threshold Securities, Working Paper, The Ohio State University.

Duffie, D., N. Garleanu, and L. Pedersen, 2002, Securities Lending, Shorting, and Pricing, Journal of Financial Economics 66, 3-7-339.

Evans, R., C. Geczy, D. Musto, and A. Reed, 2003, Failure is an Option: Impediments to Short Selling and Options Prices, working paper. 
Fama, Eugene F., and James MacBeth, 1973, Risk, return and equilibrium: Empirical tests, Journal of Political Economy 81, 607-636.

Fama, Eugene F., and Kenneth R. French, 1993, Common risk factors in the returns of stocks and bonds, Journal of Financial Economics 33, 3-56.

Fama, Eugene F., and Kenneth R. French, 1992, The Cross-Section of Expected Stock Returns, Journal of Finance 46, 427-466.

Figlewski, S., 1981, The Informational Effects of Restrictions on Short Sales: Some Empirical Evidence, Journal of Financial and Quantitative Analysis 15, 463-476.

Figlewski, S., and G. Webb, 1993, Options, Short Sales, and Market Completeness, The Journal of Finance 48, 761-777.

Geczy, C., D. Musto, and A. Reed, 2002, Stocks are Special Too: An Analysis of the Equity Lending Market, Journal of Financial Economics 66, 241-269.

Harrison, J., and D. Kreps, 1978, Speculative Investor Behavior in a Stock Market with Heterogeneous Expectations, Quarterly Journal of Economics 92, 323-336.

Holthausen, R. W., R. W. Leftwich, and D. Mayers, 1990, Large-block transactions, the speed of response, and temporary and permanent stock-price effects, Journal of Financial Economics, 26, 71-96.

Hong, H., T. Lim, and J. Stein, 2000, Bad News Travels Slowly: Size, Analyst Coverage, and the Profitability of Momentum Strategies, The Journal of Finance 55, 265-295.

Jegadeesh, Narasimhan, and Sheridan Titman, 1993, Returns to buying winners and selling losers: Implications for stock market efficiency, Journal of Finance 42, 873-888.

Jones, C., and O. Lamont, 2002, Short Sales Constraints and Stock Returns, Journal of Financial Economics 66, 207-239.

Kraus, A., and H. R. Stoll, 1972, Price impacts of block trading on the New York Stock Exchange, Journal of Finance, 27, 569-588. 
Lamont, O., 2004, Go Down Fighting: Short Sellers vs. Firms, NBER working paper 10659.

Lamont, O., and J. Stein, 2004, Aggregate Short Interest and Market Valuations, NBER Working Paper No. 10218.

Miller, E., 1977, Risk, Uncertainty, and Divergence of Opinion, Journal of Finance 32, 11511168.

Mitchell, M., T. Pulvino, and E. Stafford, 2002, Limited Arbitrage in Equity Markets, Journal of Finance 57, 551-584.

Nagel, S., 2004, Short Sales, Institutional Investors, and the Cross-section of Stock Returns, Journal of Financial Economics, forthcoming.

Newey, W. and K. West, 1987, A Simple, Positive Semi-Definite, Heteroskedasticity and Autocorrelation Consistent Covariance Matrix, Econometrica 55, 703-708.

Ofek, E., and M. Richardson, 2003, DotCom Mania: The Rise and Fall of Internet Stock Prices, Journal of Finance.

Ofek, E., M. Richardson, and R. Whitelaw, 2003, Limited Arbitrage and Short Sales Restrictions: Evidence from the Options Markets, NBER working paper No. 9423.

Reed, A., 2002, Costly Short-selling and Stock Price Adjustment to Earnings Announcements, Working paper, University of North Carolina.

Rothchild, J., 1998,The Bear Book: Survive and Profit in Ferocious Markets, John Wiley \& Sons Publishers.

Scheinkman, J., and W. Xiong, 2003, Overconfidence and Speculative Bubbles, Journal of Political Economy 111, 1183-1219.

Senchak, A., and L. Starks, 1993, Short-sale restrictions and market reaction to short-interest announcements, Journal of Financial and Quantitative Analysis 28, 177-194.

Singal, V., and L. Xu, 2005, Do Short Sellers Know More? Evidence from a Natural Experiment, working paper. 


\section{Table I}

\section{Summary Statistics}

Panel A shows short-sale trading activity of Nasdaq stocks across exchanges. It reports total number of shorted shares in a given exchange for our sample period divided by the total number of shorted shares in all exchanges for our sample period. It also reports the total number of short-sale trades in a given exchange for our sample period divided by the total number of short-sale trades in all exchanges for our sample period. Panels B and C show the descriptive statistics of short-sale related variables for the pooled sample. Small short-sale trades are transactions $\leq \$ 4,400$, Medium short-sale trades are transactions $>\$ 4,400$ and $\leq \$ 37,000$, and Big is for transactions $>\$ 37,400$. relss is the number of shorted shares divided by the number of traded shares on day $t$. Panel D shows mean relss for non-exempt trades across different stock characteristics for the pooled sample. Low (high) ME and B/M refers to market-cap and B/M at the end of $2004 \leq 33 \mathrm{rd}(>67 \mathrm{th}$ ) NYSE percentile. Low (high) instown refers to institutional ownership at the end of $2004 \leq 33 \%(>67 \%)$. Low (high) vol refers to year 2004 share turnover $\leq 33$ rd $(>67$ th) percentile. Low (high) price refers to stocks with lagged price $<5(\geq 5)$. No put refers to stocks without put options, and no threshold refers to stocks that are not on the threshold list in day $t$. The sample only includes Nasdaq stocks with CRSP share code 10 or 11 and with a price greater than or equal to $\$ 1$ at the end of year 2004 . The time period is January 3, 2005 to June 30, 2005. The sample size is 2815 stocks.

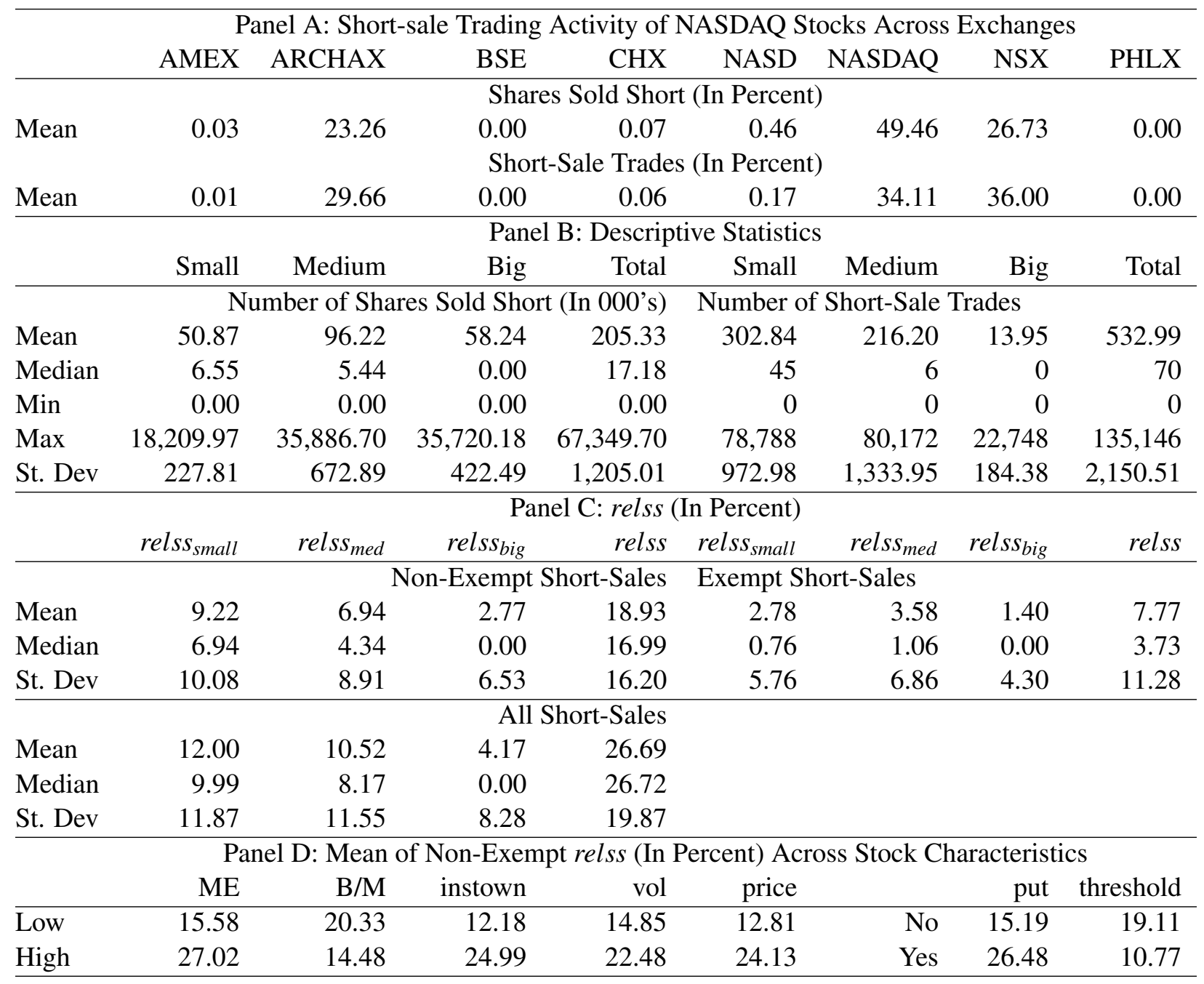



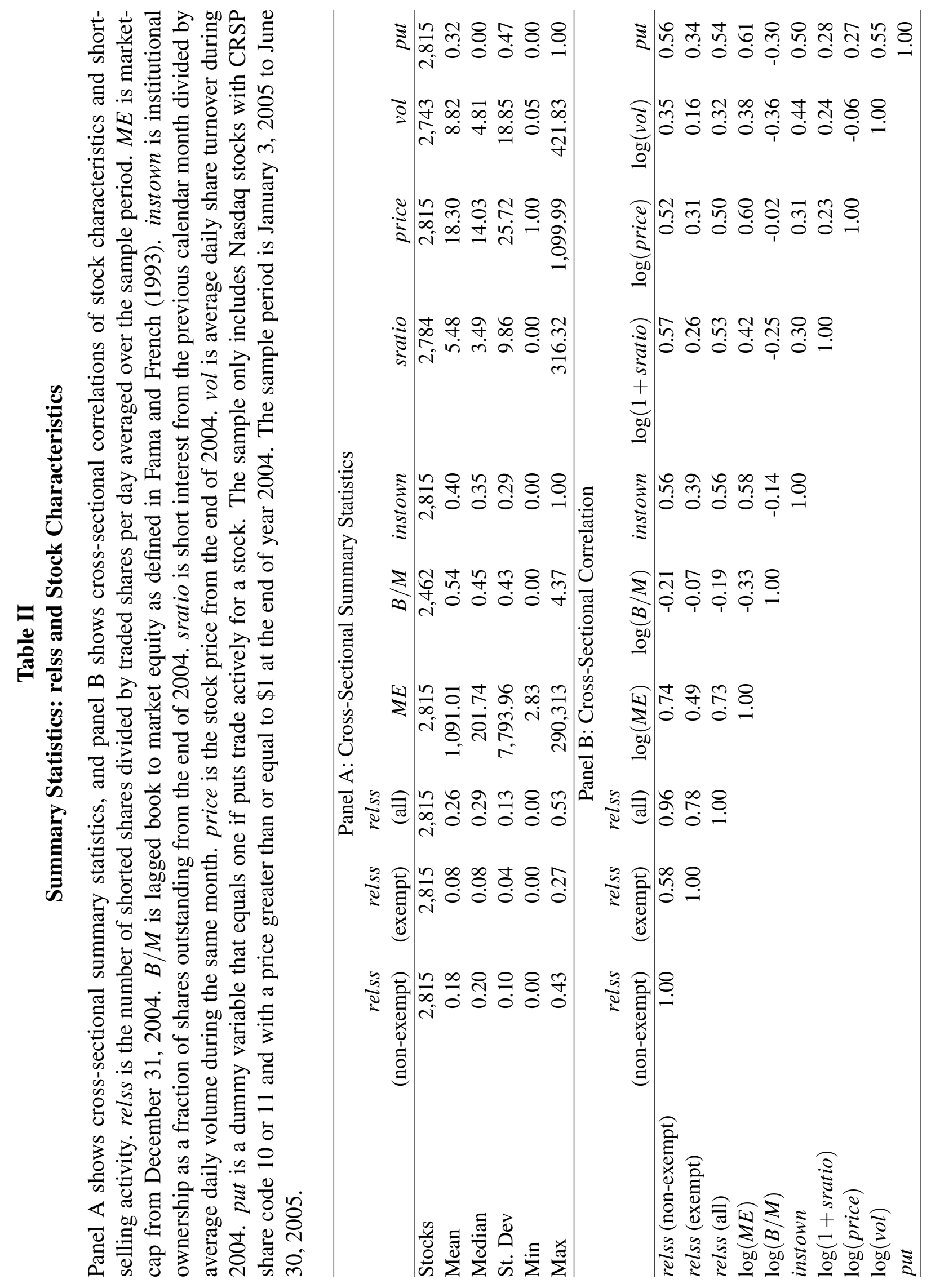


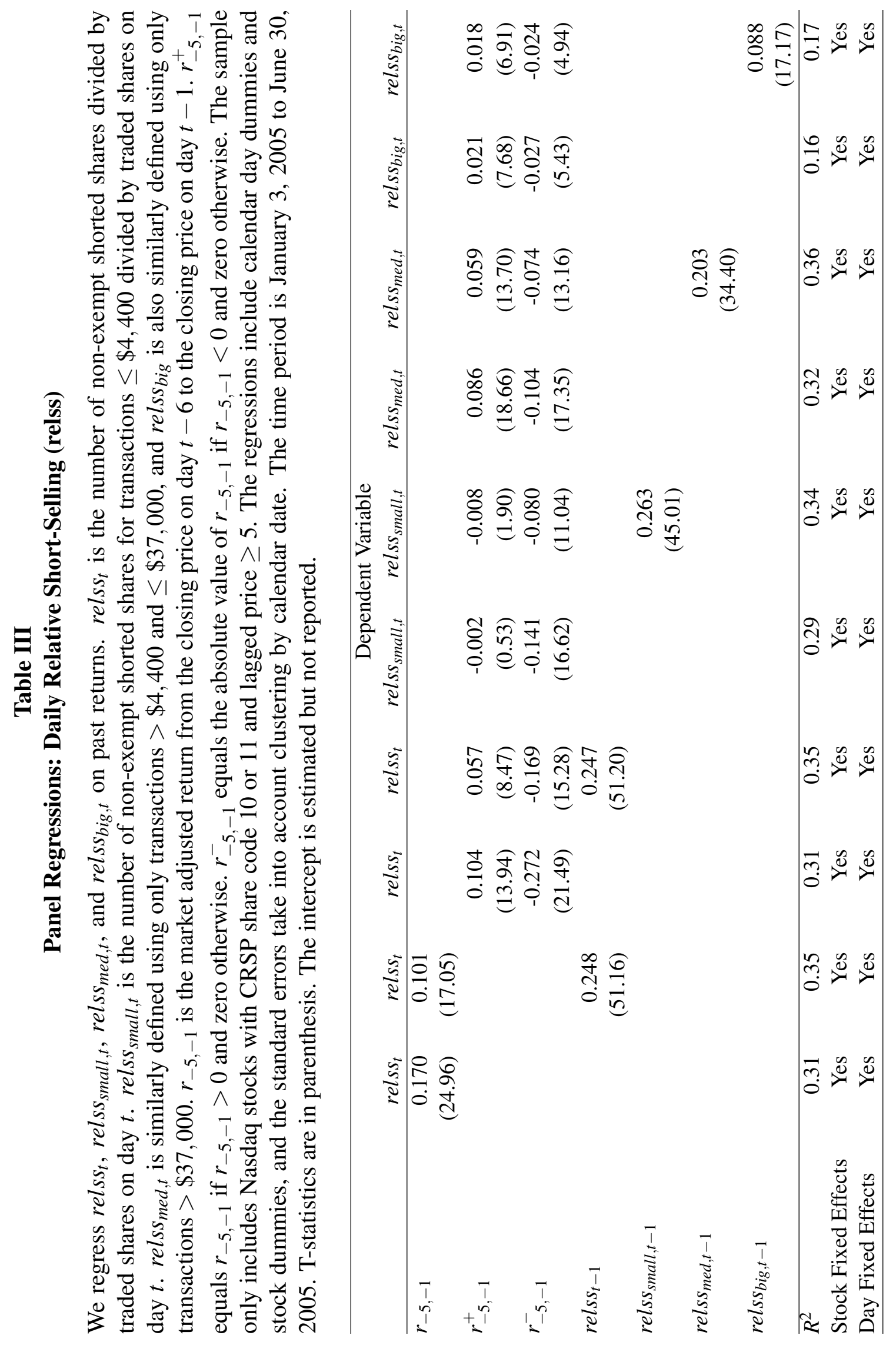




\section{Table IV}

\section{Panel Regressions: Daily Abnormal Returns in Percent}

We regress day $t+1$ stock returns $\left(r_{i, t+1}\right)$ on past shorting activity (relss). relss $s_{t}$ is the number of nonexempt shorted shares divided by traded shares on day $t$. relss $s_{\text {small,t }}$ is the number of non-exempt shorted shares for transactions $\leq \$ 4,400$ divided by traded shares on day $t$. relss $s_{m e d, t}$ is similarly defined using only transactions $>\$ 4,400$ and $\leq \$ 37,000$, and relss $_{\text {big,t }}$ is also similarly defined using only transactions $>$ $\$ 37,000 . r_{-5,-1}$ is the market adjusted return from $t-5$ to $t-1$. $r_{-5,-1}^{+}$equals $r_{-5,-1}$ if $r_{-5,-1}>0$ and zero otherwise. $r_{-5,-1}^{-}$equals the absolute value of $r_{-5,-1}$ if $r_{-5,-1}<0$ and zero otherwise. $r_{t}$ is the market adjusted return from day $t$. $M E$ is the market-cap from December 31, 2004. $B / M$ is lagged book to market equity as defined in Fama and French (1993). The sample only includes Nasdaq stocks with CRSP share code 10 or 11 and lagged price $\geq 5$. The regressions include calendar day dummies, and the standard errors take into account clustering by calendar date. The time period is January 3, 2005 to June 30, 2005. Tstatistics are in parenthesis. The intercept is estimated but not reported.

\begin{tabular}{|c|c|c|c|c|c|c|c|c|c|}
\hline \multirow[b]{2}{*}{$\overline{r e l s s} s_{t}$} & \multicolumn{9}{|c|}{ Dependent Variable: $r_{i, t+1}$} \\
\hline & $\begin{array}{l}-0.179 \\
(2.75)\end{array}$ & $\begin{array}{r}-1.072 \\
(18.48)\end{array}$ & $\begin{array}{l}-0.156 \\
(2.37)\end{array}$ & $\begin{array}{r}-0.156 \\
(2.35)\end{array}$ & & $\begin{array}{r}-0.150 \\
(1.86)\end{array}$ & & & \\
\hline relss $s_{t+1}$ & & $\begin{array}{r}2.324 \\
(33.00)\end{array}$ & & & & & & & \\
\hline$r_{-5,-1}$ & & & $\begin{array}{r}-0.010 \\
(3.29)\end{array}$ & & & & $\begin{array}{r}-0.010 \\
(3.41)\end{array}$ & & \\
\hline$r_{-5,-1}^{+}$ & & & & $\begin{array}{r}-0.010 \\
(2.57)\end{array}$ & & $\begin{array}{r}-0.015 \\
(2.67)\end{array}$ & & & $\begin{array}{r}-0.011 \\
(2.34)\end{array}$ \\
\hline$r_{-5,-1}^{-}$ & & & & $\begin{array}{l}0.009 \\
(1.60)\end{array}$ & & $\begin{array}{c}0.017 \\
(2.36)\end{array}$ & & & $\begin{array}{c}0.016 \\
(2.46)\end{array}$ \\
\hline$r_{-5,-1}^{+} *$ relss & & & & & $\begin{array}{r}-0.030 \\
(2.63)\end{array}$ & $\begin{array}{r}0.030 \\
(1.79)\end{array}$ & & & \\
\hline$r_{-5,-1}^{-} *$ relss & & & & & $\begin{array}{l}0.006 \\
(0.32)\end{array}$ & $\begin{array}{r}-0.038 \\
(1.83)\end{array}$ & & & \\
\hline relss $_{\text {small }}$ & & & & & & & $\begin{array}{r}-0.470 \\
(3.70)\end{array}$ & & $\begin{array}{r}-0.394 \\
(2.68)\end{array}$ \\
\hline relss $s_{m e d}$ & & & & & & & $\begin{array}{r}0.111 \\
(1.45)\end{array}$ & & \\
\hline relss $_{\text {big }}$ & & & & & & & $\begin{array}{r}0.131 \\
(1.34)\end{array}$ & & \\
\hline$r_{-5,-1}^{+} *$ relss $s$ small & & & & & & & & $\begin{array}{r}-0.088 \\
(3.88)\end{array}$ & $\begin{array}{l}0.018 \\
(0.68)\end{array}$ \\
\hline$r_{-5,-1}^{-} *$ relss $s$ small & & & & & & & & $\begin{array}{r}-0.025 \\
(0.70)\end{array}$ & $\begin{array}{r}-0.070 \\
(2.21)\end{array}$ \\
\hline$r_{t}$ & $\begin{array}{r}-0.058 \\
(8.57)\end{array}$ & $\begin{array}{r}-0.054 \\
(7.97)\end{array}$ & $\begin{array}{r}-0.059 \\
(8.64)\end{array}$ & $\begin{array}{r}-0.059 \\
(8.64)\end{array}$ & $\begin{array}{l}-0.059 \\
(8.75)\end{array}$ & $\begin{array}{r}-0.059 \\
(8.66)\end{array}$ & $\begin{array}{l}-0.059 \\
(8.69)\end{array}$ & $\begin{array}{l}-0.059 \\
(8.73)\end{array}$ & $\begin{array}{r}-0.059 \\
(8.61)\end{array}$ \\
\hline $\log (M E)$ & $\begin{array}{r}0.004 \\
(0.25)\end{array}$ & $\begin{array}{r}-0.048 \\
(3.55)\end{array}$ & $\begin{array}{r}0.001 \\
(0.08)\end{array}$ & $\begin{array}{r}0.001 \\
(0.07)\end{array}$ & $\begin{array}{r}-0.003 \\
(0.19)\end{array}$ & $\begin{array}{r}0.001 \\
(0.08)\end{array}$ & $\begin{array}{r}-0.009 \\
(0.56)\end{array}$ & $\begin{array}{r}-0.005 \\
(0.31)\end{array}$ & $\begin{array}{r}-0.004 \\
(0.26)\end{array}$ \\
\hline $\log (B / M)$ & $\begin{array}{l}0.032 \\
(2.13)\end{array}$ & $\begin{array}{r}0.043 \\
(2.84)\end{array}$ & $\begin{array}{l}0.032 \\
(2.16)\end{array}$ & $\begin{array}{l}0.032 \\
(2.23)\end{array}$ & $\begin{array}{l}0.031 \\
(2.15)\end{array}$ & $\begin{array}{l}0.033 \\
(2.26)\end{array}$ & $\begin{array}{l}0.032 \\
(2.11)\end{array}$ & $\begin{array}{l}0.029 \\
(2.00)\end{array}$ & $\begin{array}{l}0.031 \\
(2.16)\end{array}$ \\
\hline Day Fixed Effects & Yes & Yes & Yes & Yes & Yes & Yes & Yes & Yes & Yes \\
\hline
\end{tabular}




\section{Table V}

\section{Daily relss Portfolios: Abnormal Returns (in Percent)}

The table reports average abnormal returns for short-selling activity portfolios. In day $t$ we compute relss and relss small quintiles using all stocks in our sample. We then form portfolios using all stocks in our sample with a closing price on day $t-1$ greater than or equal to $\$ 5.00$. We compute the return on the portfolio in day $t+1$. The five day holding period portfolios use the overlapping holding period methodology of Jegadeesh and Titman (1993). relss is the number of non-exempt shorted shares divided by traded shares on day $t$. relss $s_{\text {small }}$ is the number of non-exempt shorted shares for transactions $\leq \$ 4,400$ divided by traded shares on day $t$. relss $s_{\text {big,t }}$ is similarly defined using only transactions $>\$ 37,000$. We proxy for expected returns using the CRSP value-weight market portfolio. The sample only includes Nasdaq stocks with CRSP share code 10 or 11 . The time period is January 3, 2005 to June 30, 2005. The t-statistics are adjusted for autocorrelation using the Newey-West (1987) procedure with lag=5.

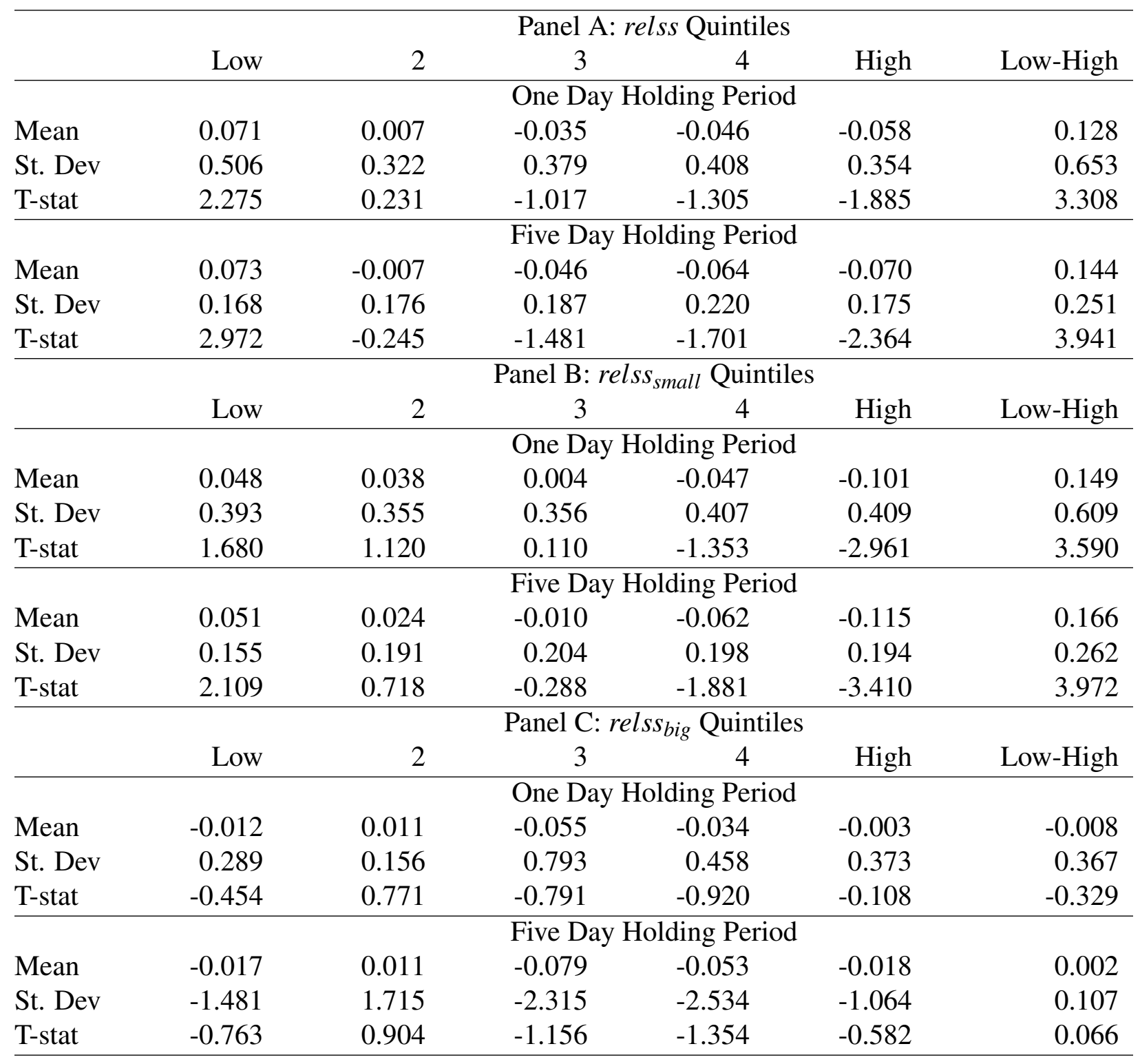




\section{Table VI}

\section{Panel Regressions: relss and Stock Characteristics}

We regress relss and relss small $_{\text {on }}$ on past returns for various sub-samples. relss is the number of non-exempt shorted shares divided by traded shares on day $t$. relss $s_{\text {small }}$ is the number of non-exempt shorted shares for transactions $\leq \$ 4,400$ divided by traded shares on day $t . r_{-5,-1}$ is the market adjusted return from the closing price on day $t-6$ to the closing price on day $t-1$. $r_{-5,-1}^{+}$equals $r_{-5,-1}$ if $r_{-5,-1}>0$ and zero otherwise. $r_{-5,-1}^{-}$equals the absolute value of $r_{-5,-1}$ if $r_{-5,-1}<0$ and zero otherwise. $M E$ is the marketcap from December 31, 2004. B/M is lagged book to market equity as defined in Fama and French (1993). instown is institutional ownership at the end of 2004. We classify stocks as small or large (growth or value) using NYSE breakpoints for $M E(B / M)$. The sample only includes Nasdaq stocks with CRSP share code 10 or 11 and lagged price $\geq 5$. The regressions include calendar day dummies and stock dummies, and the standard errors take into account clustering by calendar date. The time period is January 3, 2005 to June 30, 2005. T-statistics are in parenthesis. The intercept is estimated but not reported.

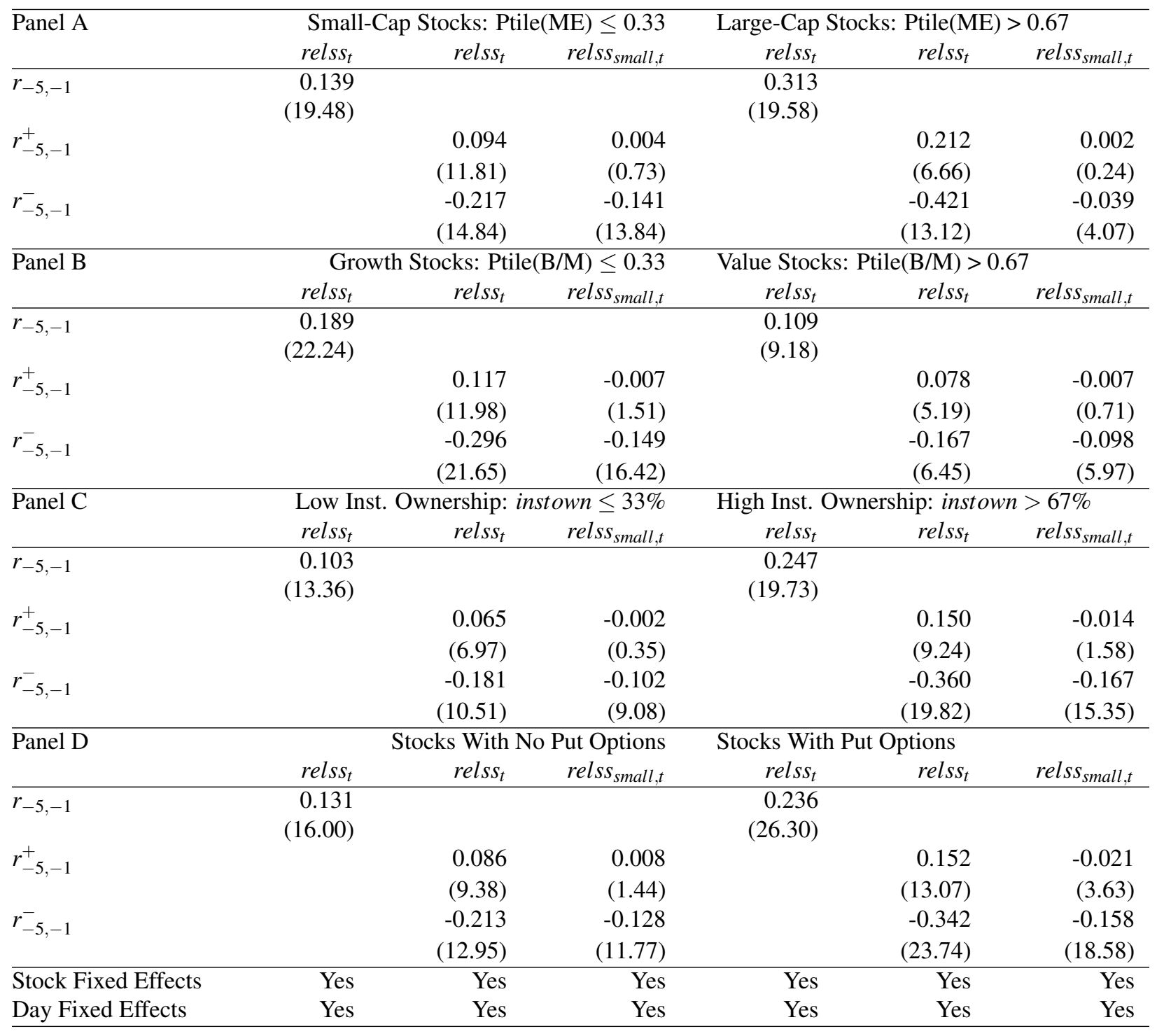


Table VII

\section{Daily relss Portfolios Disaggregated by Stock Characteristics: Abnormal Returns (in \%)}

The table reports average abnormal returns for short-activity portfolios disaggregated by various stock characteristics. In day $t$ we compute relss and relss small quintiles using all stocks in our sample. We also form market-cap (ME) terciles using NYSE market-cap breakpoints for year-end 2004 and book to market (B/M) terciles using NYSE B/M breakpoints. We also classify stocks as low (high) institutional ownership stocks if year-end 2004 institutional ownership is $\leq 33 \%$ ( $>67$ ). We then form double sort portfolios based on the intersection of relss (relss small $_{\text {suintiles }}$ and $\mathrm{ME}$ terciles, B/M terciles, institutional ownership classification, and put option availability. The portfolios include all stocks in our sample with a closing price on day $t-1$ greater than or equal to $\$ 5.00$. We compute the return on the portfolio in day $t+1$. The portfolios are rebalanced daily. relss is the number of non-exempt shorted shares divided by traded shares on day $t$. relss $s_{\text {small }}$ is the number of non-exempt shorted shares for transactions $\leq \$ 4,400$ divided by traded shares on day $t$. We proxy for expected returns using the CRSP value-weight market portfolio. The sample only includes Nasdaq stocks with CRSP share code 10 or 11. The time period is January 3, 2005 to June 30, 2005. The t-statistics are adjusted for autocorrelation using the Newey-West (1987) procedure with lag=5.

Panel A: relss Double Sort Portfolios

\begin{tabular}{|c|c|c|c|c|c|c|c|c|}
\hline \multirow{3}{*}{$\begin{array}{l}\text { relss } \\
\text { Quintiles }\end{array}$} & \multicolumn{8}{|c|}{ Mean Abnormal Returns } \\
\hline & \multicolumn{2}{|c|}{ Market-Cap } & \multicolumn{2}{|c|}{ Book to Market } & \multicolumn{2}{|c|}{ Inst. Ownership } & \multicolumn{2}{|c|}{ Put Options } \\
\hline & Small & Large & Low & High & Low & High & No & Yes \\
\hline Low & 0.070 & 0.105 & 0.016 & 0.101 & 0.075 & 0.014 & 0.072 & 0.011 \\
\hline High & -0.081 & -0.047 & -0.039 & -0.078 & -0.119 & -0.033 & -0.063 & -0.053 \\
\hline Low-High & 0.151 & 0.152 & 0.055 & 0.179 & 0.193 & 0.047 & 0.135 & 0.134 \\
\hline T-stat & 3.948 & 1.47 & 1.442 & 3.269 & 4.920 & 0.814 & 3.903 & 0.679 \\
\hline
\end{tabular}

Panel B: relss small $_{\text {Double Sort Portfolios }}$

\begin{tabular}{|c|c|c|c|c|c|c|c|c|}
\hline \multirow{3}{*}{$\begin{array}{l}\text { relss } \\
\text { Quintiles } \\
\text { Quiles }\end{array}$} & \multicolumn{8}{|c|}{ Mean Abnormal Returns } \\
\hline & \multicolumn{2}{|c|}{ Market-Cap } & \multicolumn{2}{|c|}{ Book to Market } & \multicolumn{2}{|c|}{ Inst. Ownership } & \multicolumn{2}{|c|}{ Put Options } \\
\hline & Small & Large & Low & High & Low & High & No & Yes \\
\hline Low & 0.073 & 0.000 & 0.002 & 0.107 & 0.068 & -0.001 & 0.068 & 0.008 \\
\hline High & -0.132 & -0.091 & -0.089 & -0.114 & -0.158 & -0.072 & -0.110 & -0.085 \\
\hline Low-High & 0.205 & 0.073 & 0.091 & 0.220 & 0.226 & 0.071 & 0.178 & 0.064 \\
\hline T-stat & 4.159 & 1.129 & 2.528 & 4.210 & 4.938 & 1.988 & 4.662 & 1.522 \\
\hline
\end{tabular}




\section{Table VIII \\ NYSE Short-Selling Activity}

Panel A shows the descriptive statistics of short-sale related variables for the pooled sample of NYSE stocks. relss is the number of non-exempt shorted shares divided by traded shares on day $t$. relss $s_{\text {small,t }}$ is the number of non-exempt shorted shares for transactions $\leq \$ 4,400$ divided by traded shares on day $t$. rels $s_{\text {med }, t}$ is similarly defined using only transactions $>\$ 4,400$ and $\leq \$ 37,000$, and relss $s_{\text {big }}$ is also similarly defined using only transactions $>\$ 37,000$. The sample only includes NYSE stocks with CRSP share code 10 or 11 and with a price greater than or equal to $\$ 1$ at the end of year 2004. Stocks are dropped from the sample if the number of traded shares is less than or equal to zero. The time period is January 3, 2005 to June 30, 2005. The sample size is 1435 stocks. In Panel B we regress relss, relss $s_{\text {small }}$, relss $s_{\text {med }}$, and relss big on past returns. $r_{-5,-1}$ is the market adjusted return from the closing price on day $t-6$ to the closing price on day $t-1$. $r_{-5,-1}^{+}$equals $r_{-5,-1}$ if $r_{-5,-1}>0$ and zero otherwise. $r_{-5,-1}^{-}$equals the absolute value of $r_{-5,-1}$ if $r_{-5,-1}<0$ and zero otherwise. The sample only includes NYSE stocks with CRSP share code 10 or 11 and lagged price $\geq 5$. The regressions include calendar day dummies and stock dummies, and the standard errors take into account clustering by calendar date. The time period is January 3, 2005 to June 30, 2005. T-statistics are in parenthesis. The intercept is estimated but not reported.

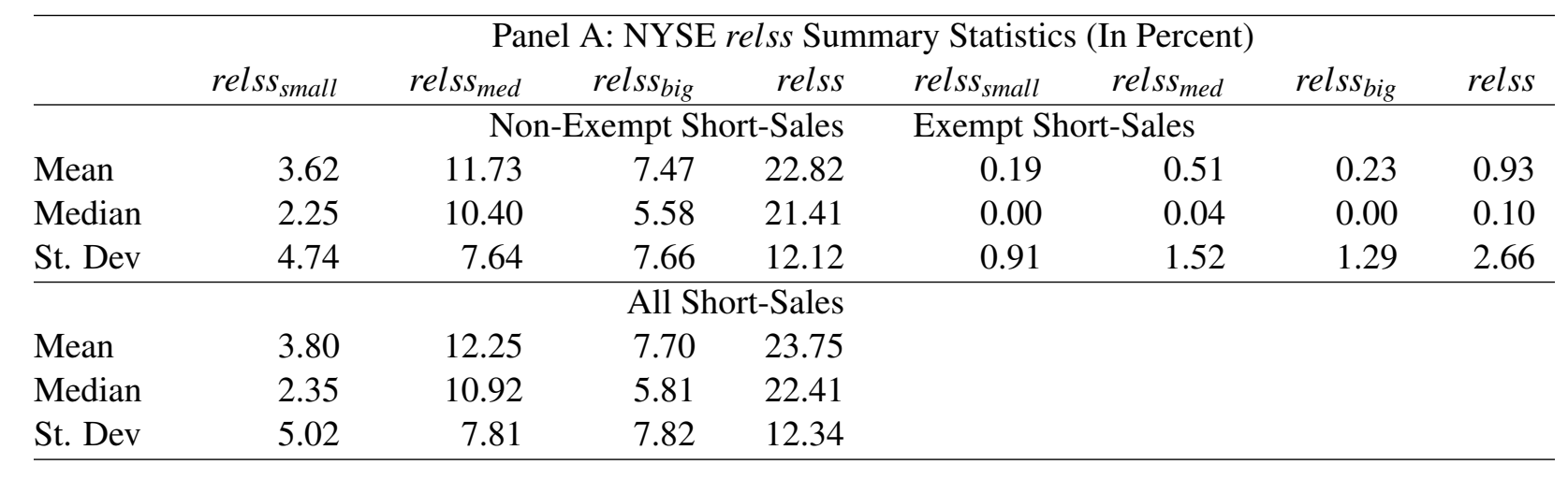

\begin{tabular}{|c|c|c|c|c|c|c|}
\hline \multirow[b]{2}{*}{ Dependent Variable } & \multicolumn{5}{|c|}{ Panel B: Daily relss Panel Regression for NYSE Stocks } & \multirow[b]{2}{*}{ relss $_{\text {big,t }}$} \\
\hline & relss $s_{t}$ & relss $s_{t}$ & relss $s_{t}$ & relss small,t & relss $s_{\text {med } . t}$ & \\
\hline \multirow[t]{2}{*}{$r_{-5,-1}$} & 0.367 & 0.162 & & & & \\
\hline & $(36.83)$ & (19.81) & & & & \\
\hline \multirow{2}{*}{$r_{-5,-1}^{+}$} & & & 0.326 & -0.019 & 0.146 & 0.200 \\
\hline & & & $(21.18)$ & $(5.12)$ & $(16.70)$ & $(21.00)$ \\
\hline \multirow[t]{2}{*}{$r_{-5,-1}^{-}$} & & & -0.417 & -0.066 & -0.246 & -0.105 \\
\hline & & & $(24.92)$ & (11.19) & (25.19) & $(11.92)$ \\
\hline \multirow[t]{2}{*}{$r e l s s_{t-1}$} & & 0.353 & & & & \\
\hline & & $(81.94)$ & & & & \\
\hline$\overline{R^{2}}$ & 0.26 & 0.35 & 0.26 & 0.54 & 0.34 & 0.36 \\
\hline Stock Fixed Effects & Yes & Yes & Yes & Yes & Yes & Yes \\
\hline Day Fixed Effects & Yes & Yes & Yes & Yes & Yes & Yes \\
\hline
\end{tabular}




\section{Table IX}

\section{Daily NYSE relss Portfolios: Abnormal Returns (in Percent)}

The table reports average abnormal returns for NYSE short-selling activity portfolios. In day $t$ we compute relss and relss small quintiles using all stocks in our sample. We then form portfolios using all stocks in our sample with a closing price on day $t-1$ greater than or equal to $\$ 5.00$. We compute the return on the portfolio in day $t+1$. The five day holding period portfolios use the overlapping holding period methodology of Jegadeesh and Titman (1993). relss is the number of non-exempt shorted shares divided by traded shares on day $t$. relss $s_{\text {small }}$ is the number of non-exempt shorted shares for transactions $\leq \$ 4,400$ divided by traded shares on day $t$. relss $s_{\text {big,t }}$ is similarly defined using only transactions $>\$ 37,000$. We proxy for expected returns using the CRSP value-weight market portfolio. The sample only includes NYSE stocks with CRSP share code 10 or 11 . The time period is January 3, 2005 to June 30, 2005. The t-statistics are adjusted for autocorrelation using the Newey-West (1987) procedure with lag=5.

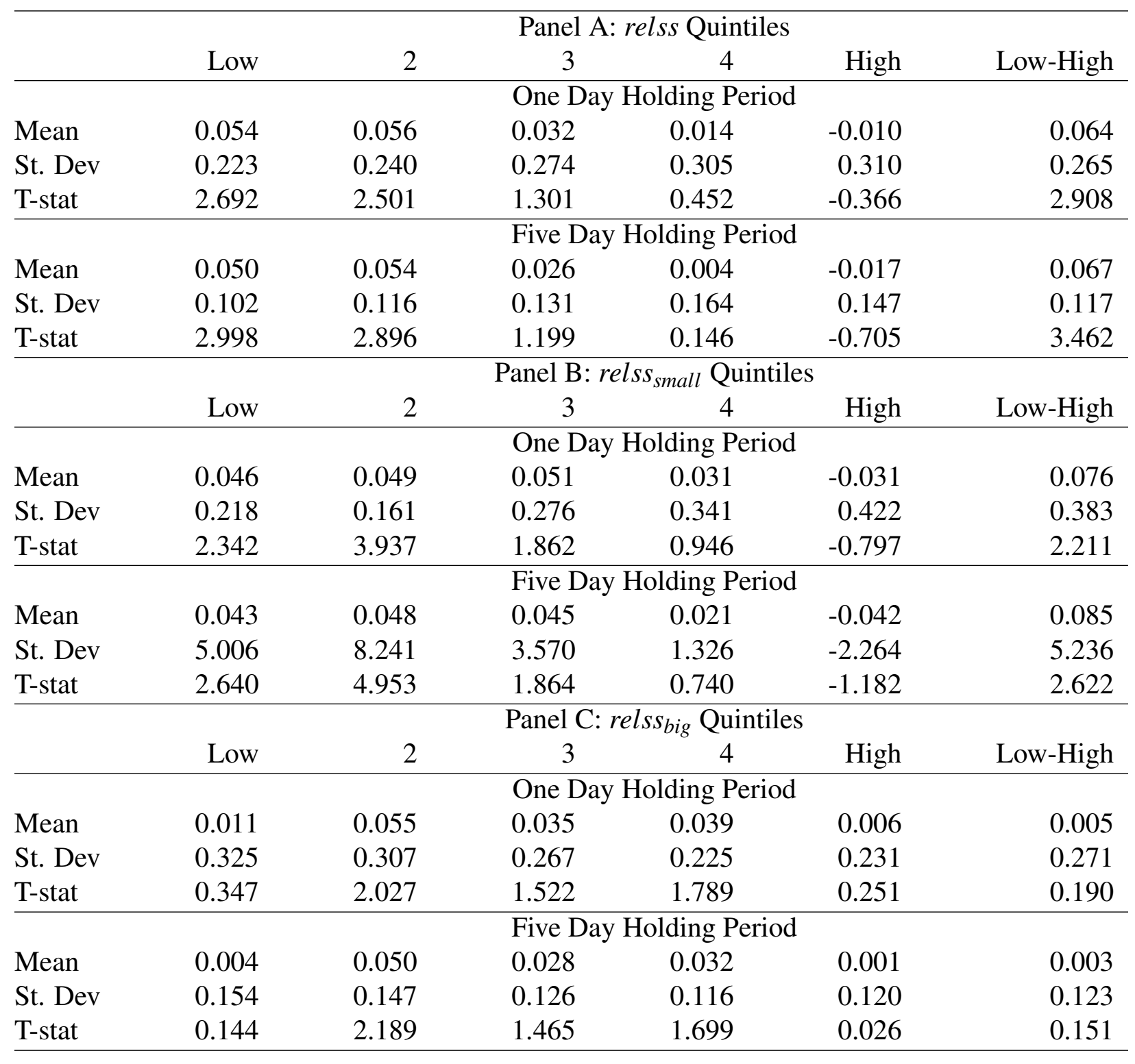



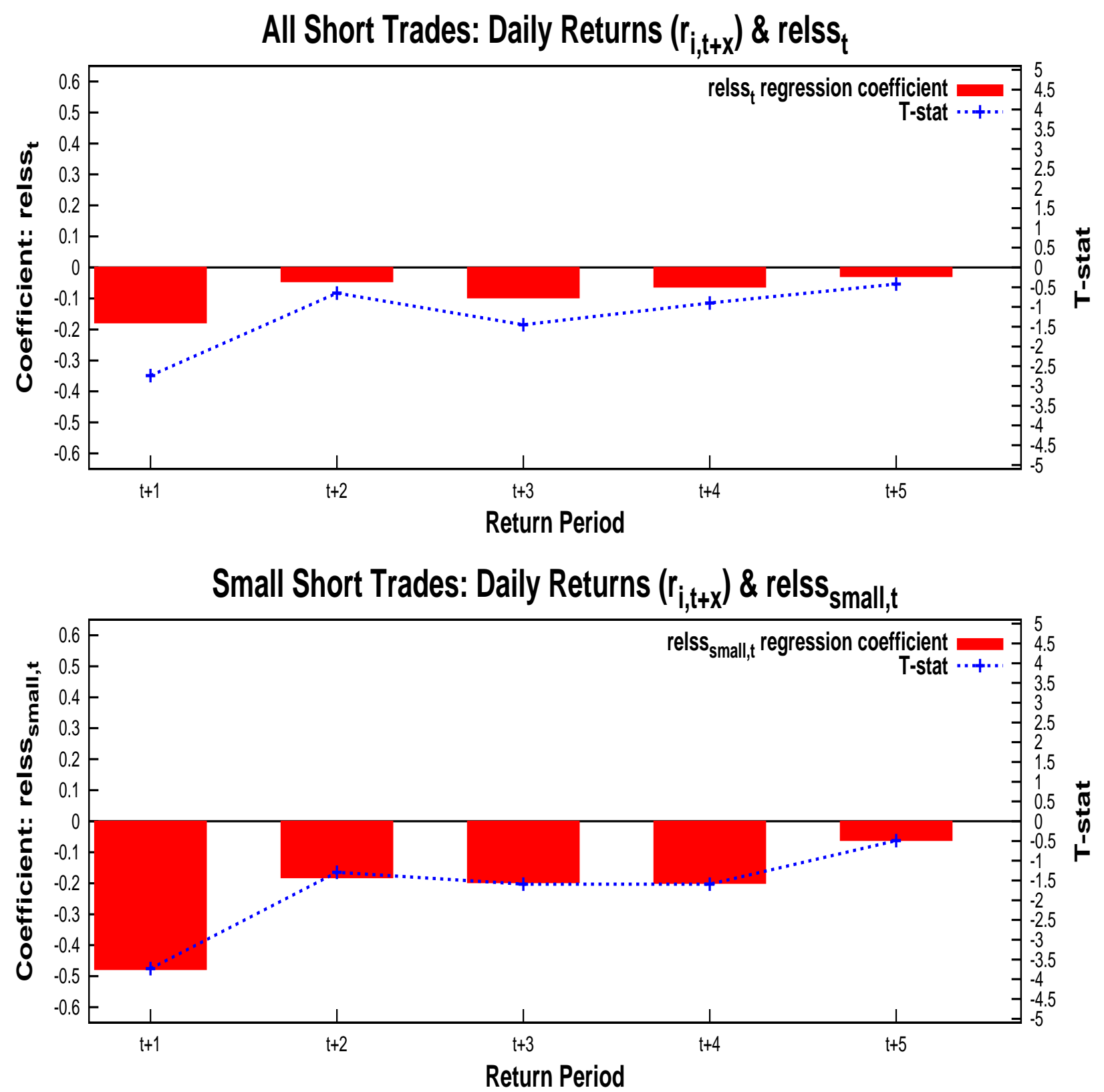

Figure 1: Daily Subsequent Returns and relss Using Cross Sectional Regressions

We regress daily returns on day $t+x\left(r_{i, t+x}\right)$ in percent on $r e l s s_{t}$ in the top plot and daily returns on

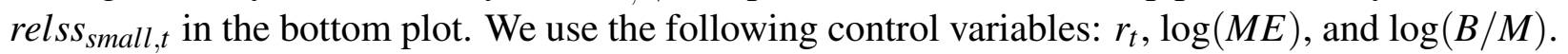
$r_{t}$ is the market adjusted return from day $t . M E$ is the market-cap from the end of 2004. $B / M$ is lagged book to market equity as defined in Fama and French (1993). The sample only includes Nasdaq stocks with CRSP share code 10 or 11 and lagged price $\geq 5$. The regressions include calendar day dummies, and the standard errors take into account clustering by calendar date. The time period is January 3, 2005 to June 30, 2005. The intercept is estimated but not reported. 

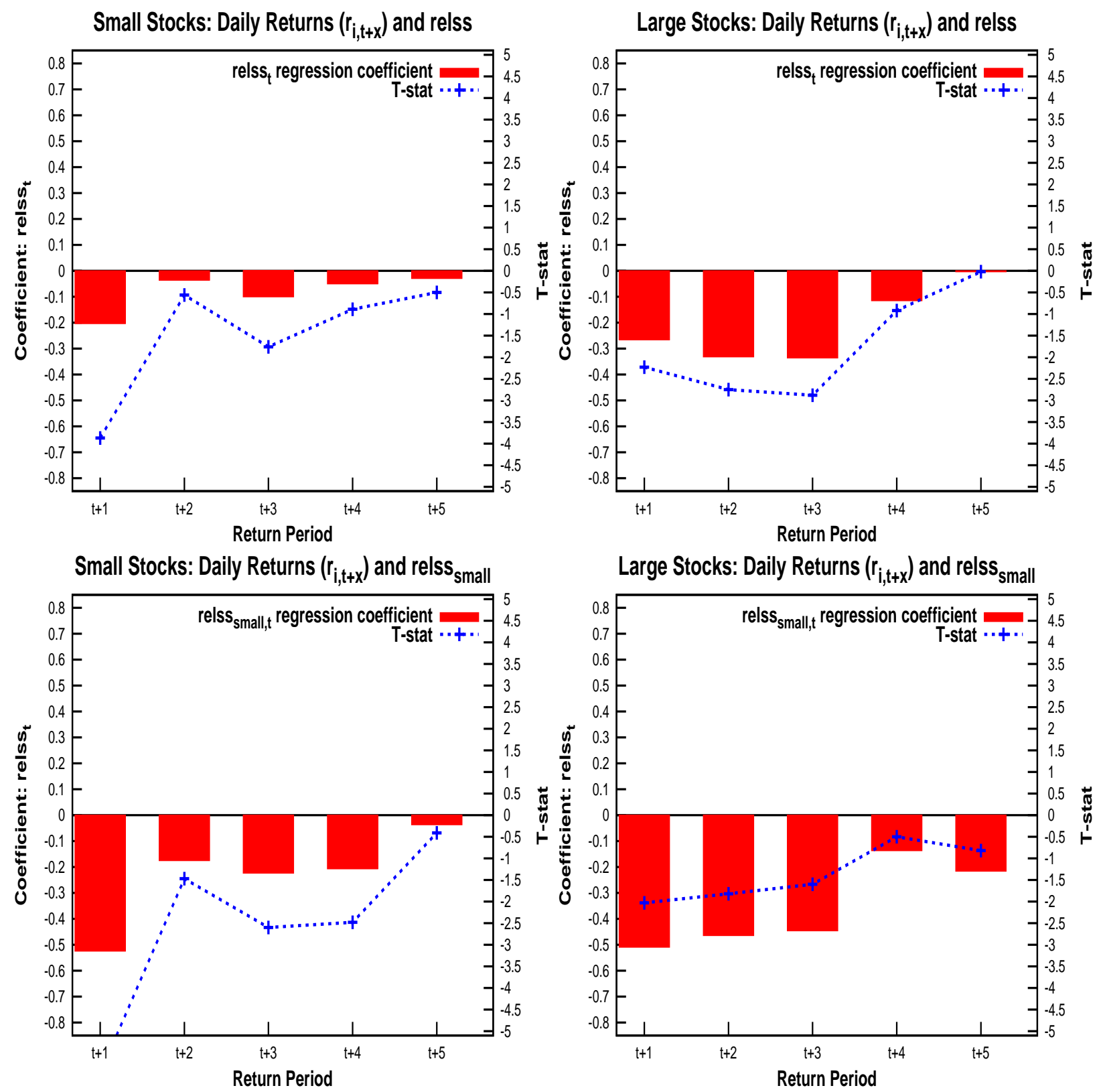

Figure 2: Daily Subsequent Returns and relss by Trade Size and Market-Cap

We regress daily returns on day $t+x\left(r_{i, t+x}\right)$ in percent on relss $s_{t}$ in the top plots and daily abnormal returns on relss small,t in the bottom plots for small and large stocks. relss $s_{t}$ and relss $s_{\text {small,t }}$ are defined as in table III. We use the following control variables: $r_{t}, \log (M E)$, and $\log (B / M) . r_{t}$ is the market adjusted return from day $t . M E$ is the market-cap from the end of 2004. $B / M$ is lagged book to market equity as defined in Fama and French (1993). We classify a stock as small (large) if it is in the bottom (top) NYSE market-cap tercile. The sample only includes Nasdaq stocks with CRSP share code 10 or 11 and lagged price $\geq 5$. The regressions include calendar day dummies, and the standard errors take into account clustering by calendar date. The time period is January 3, 2005 to June 30, 2005. The intercept is estimated but not reported. 

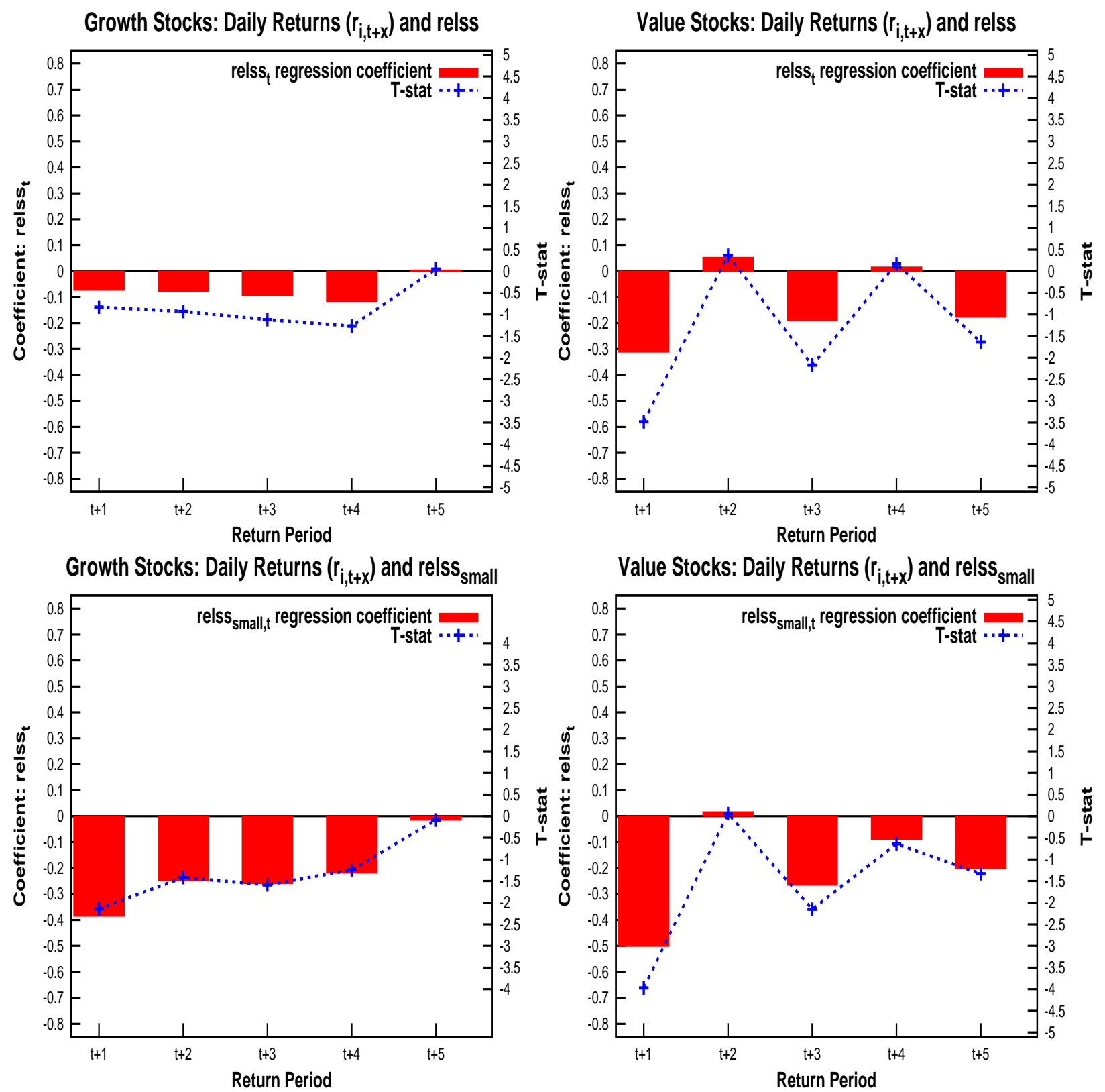

Figure 3: Daily Subsequent Returns and relss by Trade Size and Book to Market

We regress daily returns on day $t+x\left(r_{i, t+x}\right)$ in percent on $r e l s s_{t}$ in the top plots and daily abnormal returns on relss $s_{\text {small }, t}$ in the bottom plots for growth and value stocks. relss $s_{t}$ and relss $s_{\text {small }, t}$ are defined as in table III. We use the following control variables: $r_{t}, \log (M E)$, and $\log (B / M) . r_{t}$ is the market adjusted return from day $t . M E$ is the market-cap from the end of 2004. $B / M$ is lagged book to market equity as defined in Fama and French (1993). We classify a stock as growth (value) if it is in the bottom (top) NYSE market-cap tercile. The sample only includes Nasdaq stocks with CRSP share code 10 or 11 and lagged price $\geq 5$. The regressions include calendar day dummies, and the standard errors take into account clustering by calendar date. The time period is January 3, 2005 to June 30, 2005. The intercept is estimated but not reported. 

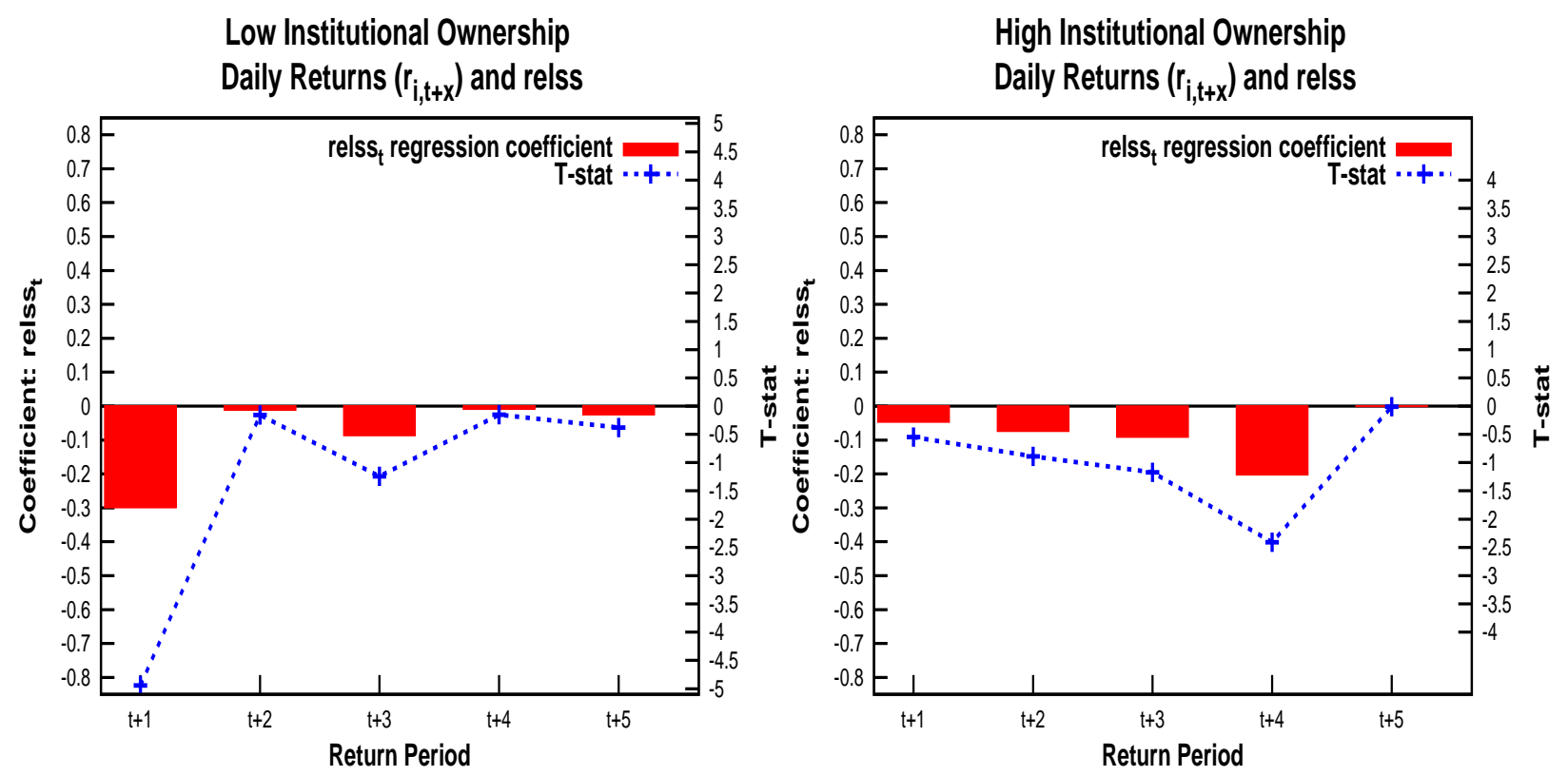

Low Institutional Ownership

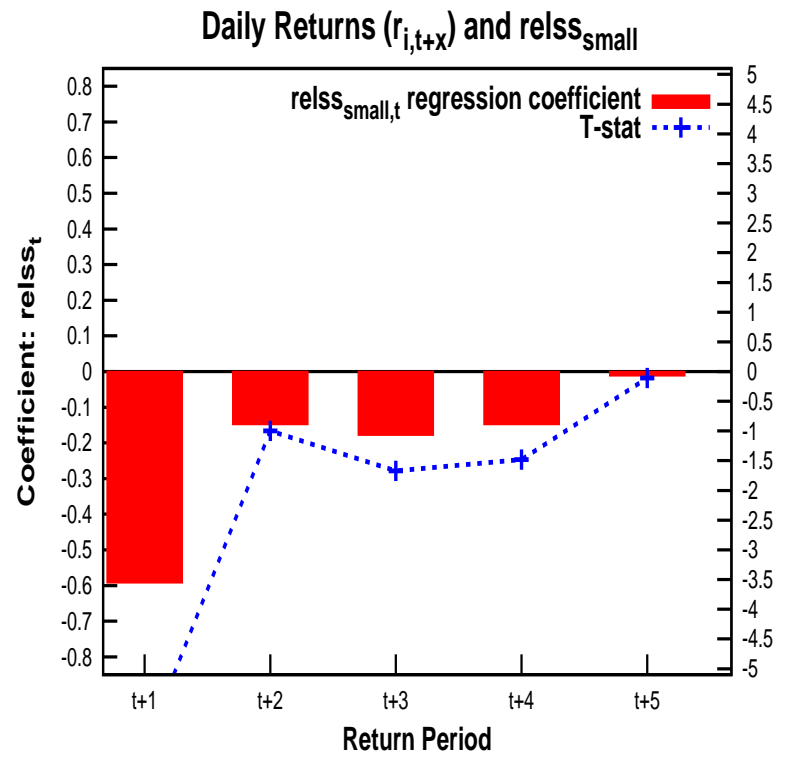

High Institutional Ownership

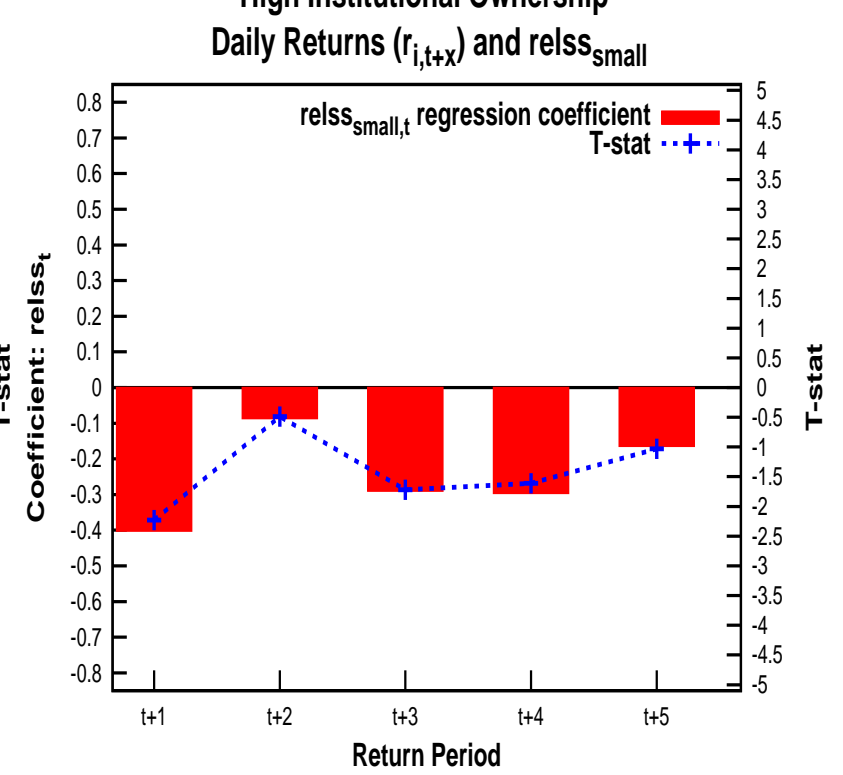

Figure 4: Daily Subsequent Returns and relss by Trade Size and Institutional Ownership

We regress daily returns on day $t+x\left(r_{i, t+x}\right)$ in percent on relss $s_{t}$ in the top plots and daily abnormal

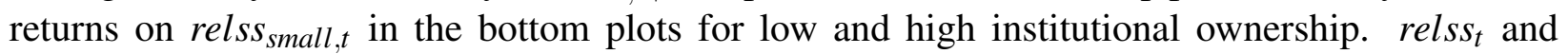
relss small,t are defined as in table III. We use the following control variables: $r_{t}, \log (M E)$, and $\log (B / M) . r_{t}$ is the market adjusted return from day $t . M E$ is the market-cap from the end of 2004. $B / M$ is lagged book to market equity as defined in Fama and French (1993). We define low (high) institutional ownership as $\leq 33 \%(>67 \%)$. The sample only includes Nasdaq stocks with CRSP share code 10 or 11 and lagged price $\geq 5$. The regressions include calendar day dummies, and the standard errors take into account clustering by calendar date. The time period is January 3, 2005 to June 30, 2005. The intercept is estimated but not reported. 
Stock Without Put Options

Daily Returns $\left(\mathrm{r}_{i, t+\mathrm{x}}\right)$ and relss

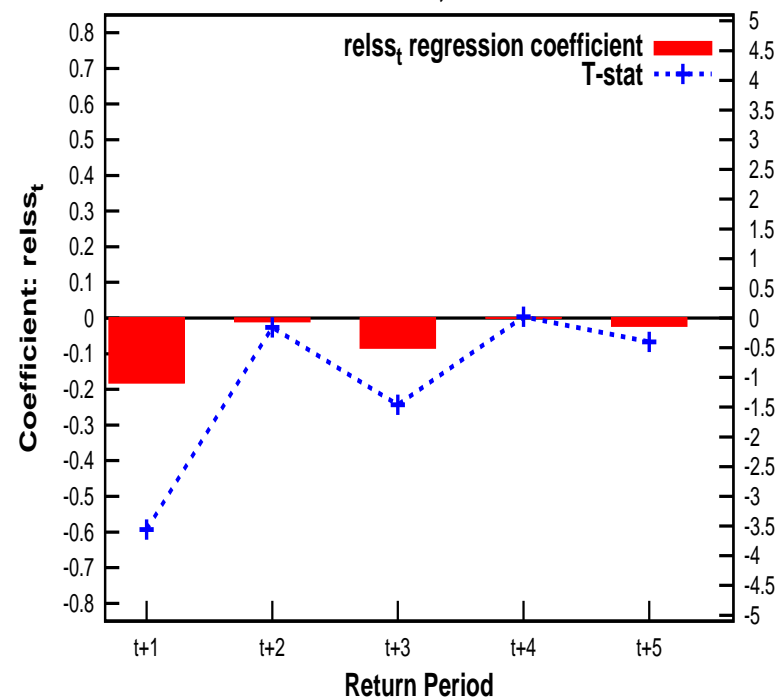

Stock Without Put Options

Daily Returns $\left(\mathrm{r}_{\mathrm{i}, \mathrm{t}+\mathrm{x}}\right)$ and relss small

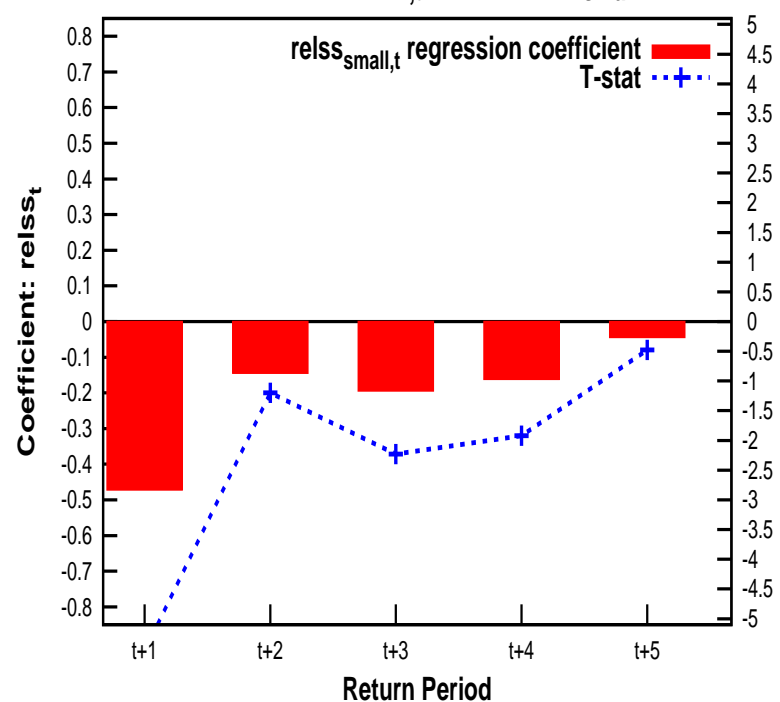

Stock With Put Options

Daily Returns $\left(\mathrm{r}_{\mathrm{i}, \mathrm{t}+\mathrm{x}}\right)$ and relss

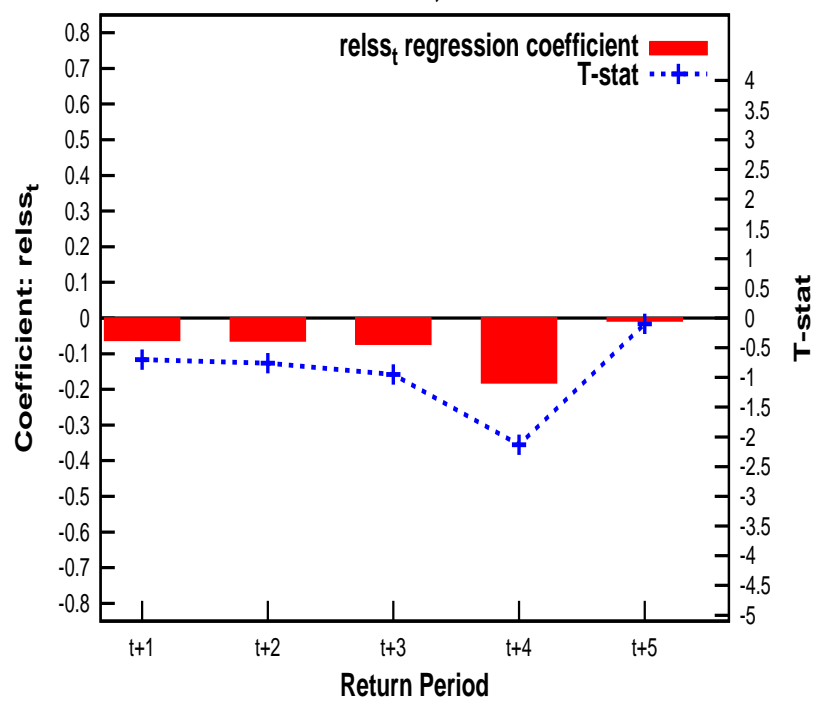

Stocks With Put Options

Daily Returns $\left(r_{i, t+x}\right)$ and relss small $_{1}$

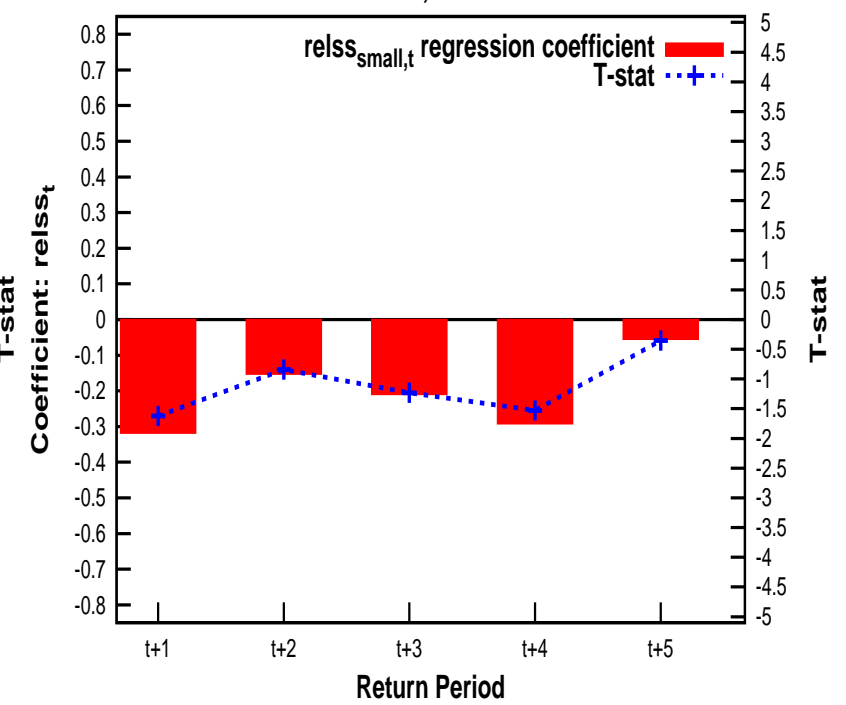

Figure 5: Daily Subsequent Returns and relss by Trade Size and Put Availability

We regress daily returns on day $t+x\left(r_{i, t+x}\right)$ in percent on relss in the top plots and daily abnormal returns on relss small,t $_{t}$ in the bottom plots for stock with and without put options. relss $s_{t}$ and relss $s_{\text {small,t }}$ are defined as in table III. We use the following control variables: $r_{t}, \log (M E)$, and $\log (B / M) . r_{t}$ is the market adjusted return from day $t . M E$ is the market-cap from the end of 2004. $B / M$ is lagged book to market equity as defined in Fama and French (1993). The sample only includes Nasdaq stocks with CRSP share code 10 or 11 and lagged price $\geq 5$. The regressions include calendar day dummies, and the standard errors take into account clustering by calendar date. The time period is January 3, 2005 to June 30, 2005. The intercept is estimated but not reported. 